\title{
NON-LINEAR STATIC AND DYNAMIC ANALYSIS OF ROCKING MASONRY CORNERS USING RIGID MACRO-BLOCK MODELLING
}

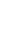

\section{Claudia Casapulla ${ }^{a *}$, Linda Giresini ${ }^{b}$, Luca Umberto Argiento ${ }^{a}$, Alessandra Maione ${ }^{a}$}

${ }^{a}$ Department of Structures for Engineering and Architecture, University of Naples Federico II, via Forno Vecchio 36 ,

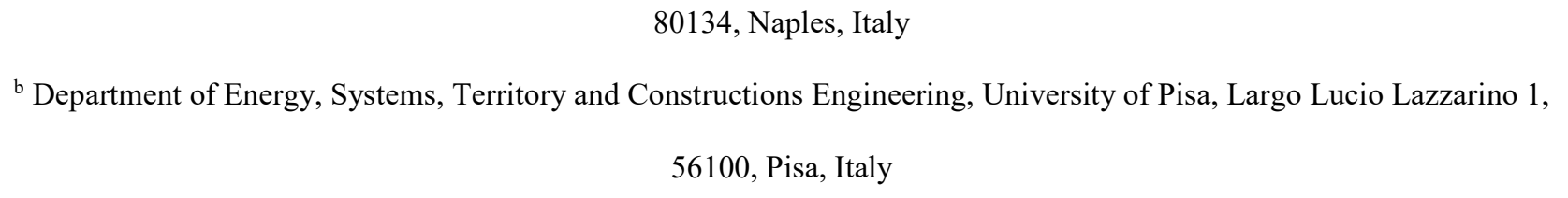

${ }^{\mathrm{b}}$ Department of Energy, Systems, Territory and Constructions Engineering, University of Pisa, Largo Lucio Lazzarino 1, 56100, Pisa, Italy

*Corresponding author (Claudia Casapulla)

$\mathrm{Ph} / \mathrm{fax}:+390812538901$

E-mail: casacla@unina.it

\section{ABSTRACT}

The corner failure is one of the most typical local mechanisms in masonry buildings vulnerable to earthquakes. The seismic assessment of this mechanism is poorly studied in the literature and in this paper it is addressed by means of both non-linear static and dynamic analyses of rocking rigid blocks. The static approach is based on the displacement-based method and is aimed at predicting the onset of the 3D failure mechanism and its evolution through incremental kinematic analysis. This approach also considers the presence of a thrusting roof and the stabilising contribution of frictional resistances exerted within interlocked walls. The capacity in terms of both forces and displacements is compared with the seismic demand through the construction of acceleration-displacement response spectra, with some originality. The non-linear dynamic approach is based on the seminal Housner's work on rocking rigid blocks and considers the influence of transverse walls, roof overloads and outward thrust, all included in an updated equation of one-sided motion. In particular, the process of defining an equivalent prismatic block, representative of the original corner geometry, is presented to convert the $3 \mathrm{D}$ dynamic problem into a $2 \mathrm{D}$ rocking motion. The wide suitability and advantage of such modelling approaches to assess the seismic response of rocking masonry structures with reference to specific limit states are demonstrated through a real case study, i.e. the collapse of a 
corner in a masonry school building during the 2016-17 Central Italy seismic sequence. The compared results provide a good agreement of predictions in terms of both onset and overturning conditions, for which the static model appears to be more conservative than the dynamic one.

\section{KEYWORDS}

Incremental kinematic analysis, dynamics of rigid blocks, out-of-plane behaviour, frictional resistances, horizontal restraint, 2016-17 Central Italy Earthquakes.

\section{INTRODUCTION}

The "box-type" behaviour of a masonry building generally requires the presence of well-connected walls and floors and a proper horizontal stiffness of the floors. In this case, proper modelling procedures can be adopted to simulate the in-plane effects of seismic actions on buildings, possibly experimentally evaluating the masonry mechanical properties [1]. All modern codes for seismic design of new masonry buildings usually provide dimensioning and detailing regulatory requirements that make out-of-plane failure almost improbable to occur even under severe seismic load.

Conversely, in masonry buildings without a box-type behaviour, such as most existing masonry buildings in the historic city centres, local out-of-plane failures can take place, especially of peripheral walls and even under low intensities of ground motion [2]. In fact, the main deficiencies in such buildings are the lack of proper connections between orthogonal walls, the absence of connecting ties, insufficiently rigid floor diaphragms, low strength and deterioration of materials; the presence of openings and their position in the walls are further relevant aspects. In addition, the low strength/mass ratio of such structures increases their vulnerability in out-of-plane direction since inertia forces are not restrained because of reduced stiffness and strength of the masonry walls in that direction.

It has been recognized, in particular, that the most recurrent failure modes caused by seismic forces acting orthogonally to the building walls involve overturning mechanisms, which can be represented by simple or complex rocking of parts of masonry walls. In case of simple rocking, poor wall-to-wall and wall-to-horizontal structure connections and/or flexible horizontal structures cause the separation of orthogonal walls and the single walls start to rock separately under seismic excitations (Figure 1a). The complex rocking, instead, can be caused by similar conditions but with good wall-to-wall connections and it refers to rocking walls together with parts of orthogonal walls (Figure 1b) or rocking corners (Figure 1c). These kinds of local failure generally occur when a monolithic behaviour can be guaranteed for walls so that they can be regarded as rigid blocks. 

dynamic fields, i.e. the pioneering Heyman's and Housner's works respectively $[3,4]$.

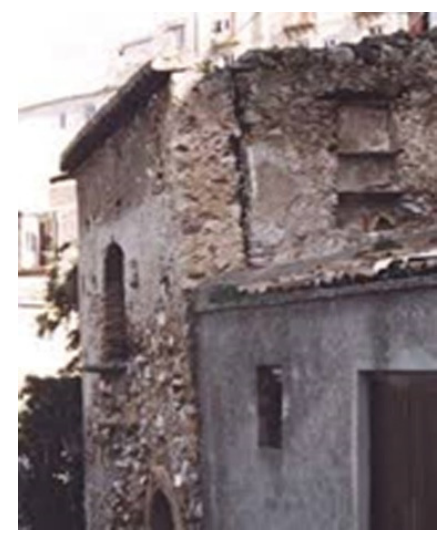

(a)

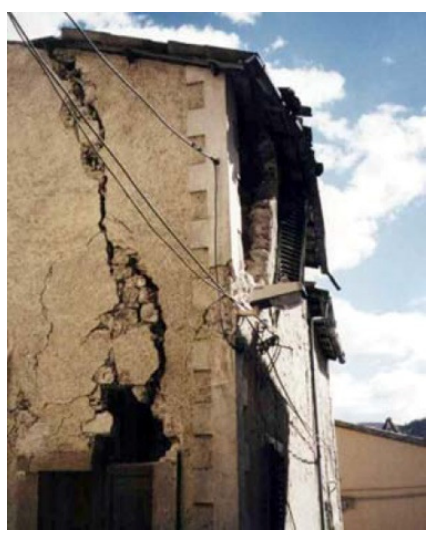

(b)

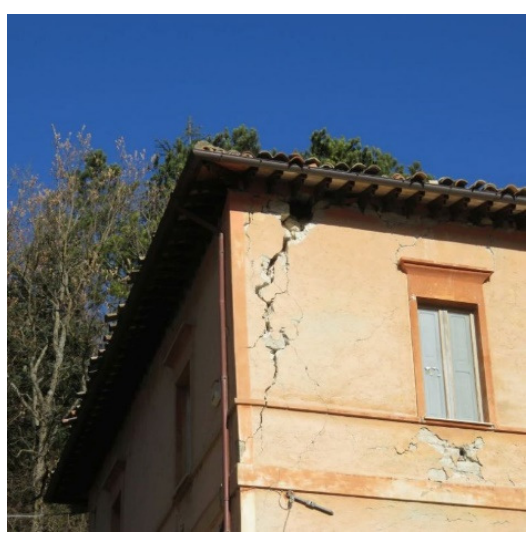

(c)

Figure 1 Simple (a) and complex (b) rocking of masonry walls; corner failure as complex rocking of masonry walls

(c).

However, the assessment of the rocking and overturning response of rigid blocks to earthquakes is still a complex task due to the large variability of the mechanical properties of the materials, the uncertainty about the construction sequence and the high sensitivity of the models to the input motion, variations in geometry and dissipation issues, especially for historical constructions [5-7]. Several methods and tools based on different approaches have lately been attempted to address this complex but valuable topic. In fact, as comprehensively discussed in [8-11], there is a large quantity of literature focused on force-based, displacement-based and rocking approaches. Some addressed aspects are also valuable to evaluate structural and energy retrofitting strategies for masonry walls [12,13].

On the other hand, despite the increasing interest of the scientific community in this topic, there is still a lack of reliable modelling strategies to statically and dynamically simulate all the types of local mechanisms and to include the significant contributions of possible restraints of the failing parts of masonry [14-16]. In particular, the corner failure involving a complex three-dimensional motion is still poorly investigated. In fact, although this kind of failure has frequently been observed in seismic scenarios, only few analytical works [17-20] and experimental investigation [21] devoted to it were found in the literature. Generally, it can occur when at least one corner of the building is free, without any adjacent structures, i.e. for buildings isolated or positioned at the end of a block. The vulnerability of this mechanism is increased by the destabilizing contribution of the roof (Figure 1c) and the presence of openings near the edge. 
To fill this gap of the literature, this paper is particularly focused on the modelling of rocking masonry corners by means of two approaches in comparison: the non-linear static and dynamic models, based on the limit analysis method and the Housner's theories of rocking rigid blocks, respectively. The two models of the rocking masonry corners are extensively discussed in their assumptions, theoretical background and field of application, with particular focuses on their novel aspects with respect to the previous works on this failure mechanism. The potential of the two approaches in defining the onset and overturning conditions of any rigid block and in evaluating its seismic safety will be shown for a particular case study: the collapse of a corner in a masonry school building during the 2016-17 Central Italy seismic swarm.

As far as the non-linear static analysis is concerned, the modelling approach is based on the displacement-based method aimed at predicting both the onset failure mechanism of the rocking rigid block and the evolution of its motion in large displacements. The solution procedure follows the incremental kinematic analysis proposed by Lagomarsino [22], which is herein developed to include the contribution of frictional resistances and a thrusting roof. The onset of the symmetric and non-symmetric corner failure has already been described in [19,21], through the minimization of the load factor. Instead, the evolution of the motion in large displacements is originally developed in this paper in order to construct pushover curves, capacity curves of the equivalent non-linear Single Degree Of Freedom system (SDOF) and capacity thresholds representing defined limit states. When the model is applied to the real case study, its capacity in terms of both forces and displacements is compared with the seismic demand through the construction of Acceleration-Displacement Response Spectra (ADRS) [23]. To this aim, another novel aspect of the model is presented: its capability of treating the $3 \mathrm{D}$ problem as $2 \mathrm{D}$ problems by considering the superimposition of these curves along the planes of the two interlocked walls. This strategy is also necessary to meet the availability of the recorded seismic inputs in these two directions.

As regards to the non-linear dynamic analysis of rigid blocks, which started with the pioneering Housner's work, the masonry walls are assumed as rigid; their motion takes into account dissipation of energy over each impact. The model is extremely intuitive, and, although bouncing and sliding are neglected, it was demonstrated to be quite reliable to reproduce the real behaviour of monolithic masonry walls [14,24]. Similarly to non-linear static analysis, also rocking analysis can be applied to a masonry element, both in free condition (namely, without added restraints such as tie-rods) and in a configuration where horizontal restraints, such as transverse walls and steel tie-rods, are active during motion, both in one-sided and two-sided conditions $[25,26]$. In particular, the three-dimensional motion of the rocking masonry corner, in principle complex to treat, is originally simplified into a two-dimensional problem, where a prismatic equivalent block is associated to the corner mechanism. 
In sum, the novel contributions of this paper can be recognized not only in the investigation of the corner failure in masonry buildings, which is still poorly studied in the literature, but also in the great suitability of each of the two proposed approaches to represent the 3D motion of the complex out-of-plane mechanism and in the interesting comparison of their results. The paper is organized as follows. Sections 2 and 3 contain the fundamentals of the non-linear static and non-linear dynamic analysis in theoretical and analytical terms, discussing the procedures to apply them to the case of the corner failure in masonry buildings. Section 4 presents the application of the analysis methods to a real case study, i.e. the collapse of a corner in a masonry school building during the 2016-17 Central Italy seismic sequence. The results of the two presented approaches are compared and discussed in Section 0 with reference to specific limit states and with a particular insight in the actual onset and the near-collapse conditions. Some conclusions are drawn in Section 6.

\section{NON-LINEAR STATIC ANALYSIS OF ROCKING CORNERS}

118 According to the kinematic approach of the equilibrium limit analysis, local mechanisms in masonry buildings can be considered as kinematic chains of masonry portions, regarded as rigid macro or micro-block assemblages, interacting through interface elements [3]. Horizontal static actions, expressed as a percentage of the dead loads by means of a load factor, are applied to the centre of mass of each moving element, in addition to all the other external loadings. The horizontal acceleration causing the mechanism is defined depending on the load factor. Therefore, in formulating all the feasible mechanisms, the lowest value of the load factors expressing limit equilibrium configurations corresponds to the onset of the most likely failure mode and to the maximum capacity of the wall to resist earthquakes. According to the displacement-based method, pushover curves can then be obtained from the static load factors (non-linear static analysis). These are obtained by the application of the theorem of virtual works, considering varied kinematic configurations of the examined mechanism, in large displacements. Along this incremental kinematic analysis, the contribution of links is taken into account, till the ultimate equilibrium condition [22,27]. Despite its simplicity, this approach becomes rather complicated when frictional resistances are taken into account, as generally occurs in actual failures [17]. In fact, proper assumptions need to be made on the flow rules to define associative or non-associative solutions when using limit analysis [28]. These assumptions involve important implications on the value of collapse load multiplier and the failure mechanism, considering that, generally speaking, non-associated flow rules do not guarantee unique solutions to the limit analysis problems (non-standard limit analysis) [29]. In addition, for complex mechanisms, interactions among rocking, sliding and twisting of connected rigid macro or micro-blocks should be taken into 
account to define the most likely in-plane or out-of-plane failure mechanisms, at the onset and during the evolution of the kinematic chain [30].

An advanced macro-block modelling approach including frictional resistances [19,31] has demonstrated to be capable of approaching the "exact" solutions for both in-plane and out-of-plane onset of mechanisms, with better results in comparison with other macro and micro-block models, also with the great advantage of obtaining such solutions with a considerably lower computational effort than the micro-block modelling approaches. This model is also suitable to perform pushover analyses using incremental kinematics, as shown in [15] for simple rocking walls weakly connected with sidewalls and in this paper for the complex rocking corner.

Therefore, it can be applied to any kind of local failure mechanism in masonry buildings, provided that the external and internal loadings are clearly defined. In the following, an accurate evaluation of the frictional resistances and the definition of reliable collapse load factors are developed. The pushover curves and the ADRS superimposed to the capacity curves will be presented in Section 4 with reference to the selected real case study.

\subsection{Rigid macro-block model}

The adopted macro-block model is based on the assumptions for the constituent micro-blocks (or units) of infinite strength in compression, tension and shear and no-tension and frictional behaviour at their contact interfaces (Coulomb failure criterion) [27]. Masonry block walls with regular units and staggering are concerned (single-leaf walls arranged in a running bond pattern), the cracking and crushing of micro-blocks are ignored and the plastic dissipation due to friction is reduced to contact interfaces. The cracks are considered as average inclinations of the discontinuous lines following the disposition of joints which tends to separate the walls in macro-blocks. The crack pattern of the mechanism is represented by the inclination of the crack lines, which are not assigned a priori but are variables of the problem, depending on geometrical and mechanical parameters.

With reference to the corner failure in a masonry building, which generally involves well-connected masonry walls under orthogonal forces, the possible mechanism can be simplified as a combination of two failure modes: the rocking-sliding failure, with the formation of two main cracks that break the continuity of the interlocked walls [19], and the horizontal flexure failure, with the formation of two macro-blocks rotating around three cylindrical hinges [21]. The geometrical parameters, mainly the unit shape, strongly affect the prevalence of one over the other and in this paper only the rocking-sliding failure is considered, while neglecting the flexural effects. This is the case of walls composed of rather square blocks, as those belonging to the real case study analyzed in Sections 4 and 5. This failure mode is characterized by a prismatic wedge rotating around a 
hinge placed at its vertex, involving rocking-sliding motions along the crack lines. Mostly, the corner failure involves the top level of a masonry building for the whole floor height since it is mainly activated in the presence of roofs inclined in both directions and openings very close to the edges. Figure 2a presents a recurrent geometry of the corner failure with the presence of openings within the interlocked walls. These are denoted Wall 1 and Wall 2, respectively oriented along the Cartesian $\mathrm{Y}$ and $\mathrm{X}$ axes, and are assumed to have the same thickness $s$, for the sake of simplicity. The wedge, identified by the main cracks, is highlighted in pink colour and the overloads of a hipped roof are assumed to be transferred by a hip rafter to the intersection of the walls, disposed along the bisector plane of the corner, as commonly occurs. The overloads are the inertial forces and the static thrust $T_{s}$ inclined of $45^{\circ}$ with respect to $\mathrm{X}$ and $\mathrm{Y}$ axes. Point $\mathrm{G}$ is the centre of all the involved masses, e.g. the mass of the rocking macro-block plus the masses of the roof. Due to non-symmetric conditions in geometry and loading of the 3D failure mechanism, the vertical plane of rotation does not coincide with the corner bisector plane. In fact, the inclination $\gamma$ of its trace OG on the horizontal XY-plane with respect to YZ-plane is dependent on the geometry of the unknown crack pattern (Figure 2b) and therefore on the coordinates of point G. On the other hand, it is easy to recognize that the direction of the horizontal forces and the frictional resistances is parallel to the line joining OG and the rotation axis $\omega$ is orthogonal to this line on the horizontal plane. The internal and external actions displayed on Figure 2 are: $F$ in different positions as the weighted frictional resistances, $W$ as the generic weights and overloads and $T_{s}$ as the horizontal thrust transferred by the hip rafter. In particular, $F$ are evaluated by applying the criterion proposed and updated in previous works [19,31]. This criterion concerns the formulation of the frictional resistances in function of the variable inclinations of the crack lines, based on the occurrence that these resistances tend to their maximum values as the crack lines tend to the vertical direction, while approaching zero as the crack lines tend to their maximum values, i.e. the half-unit shape line. The latter is defined as the angle $\alpha_{b}=\tan ^{-1}\left(v / h_{b}\right)$, where $v=l_{b} / 2$ is the overlapping length between two units (Figure 2c). According to this criterion, the resultant frictional resistances activated along the inclined crack lines of the rocking corner strictly depend on the inclination angles and should also account for the contribution due to the overloading in addition to the own weight of the interlocked walls. In fact, the upper bound of the actual frictional resistance for each wall is given by the maximum resultant of these two contributions, i.e.:

$$
F_{\max }=F_{W}+F_{Q}
$$

where: 


$$
F_{W}=\sum_{1}^{n} S_{i}=W_{b} \frac{n(n+1)}{2} f ; \quad F_{Q}=q n v f
$$

191

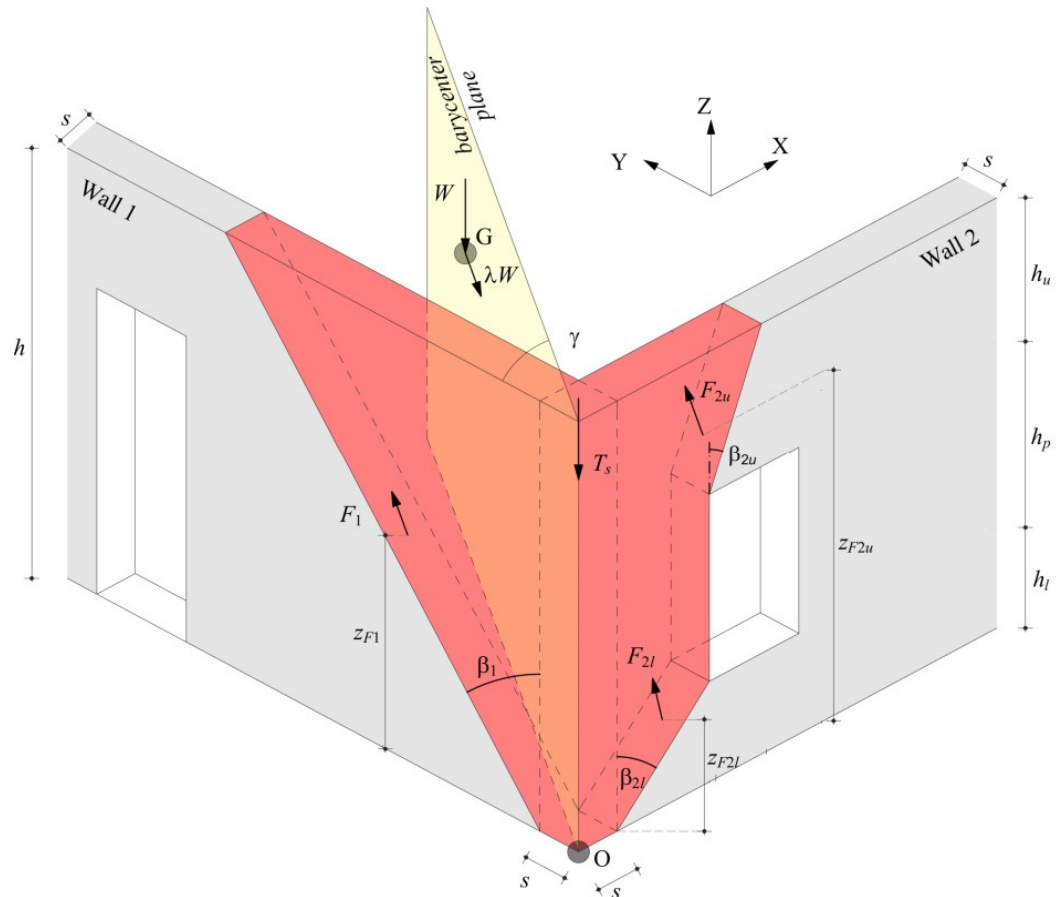

(a)

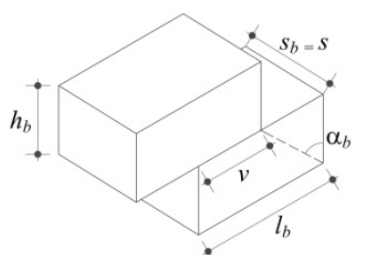

(c)

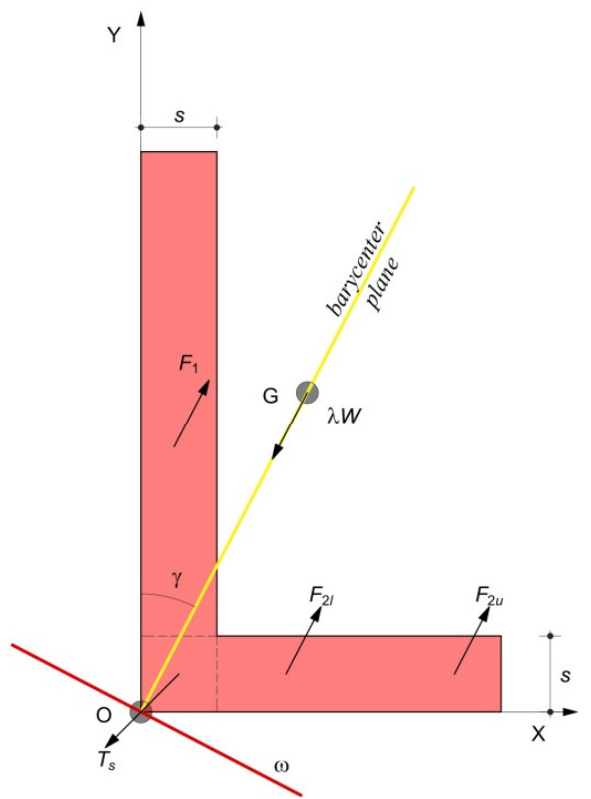

(b)

Figure 2 Corner failure (a), projection of the rocking wedge on the horizontal XY-plane (b), masonry unit dimensions (c).

Specifically, $S_{i}$ is the limiting shear force due to friction at contact interface $i, W_{b}$ is the weight of a single half-unit, $n$ is the number of rows along the wall height, $f$ is the friction coefficient, while $q$ is the uniformly distributed overload for unit of wall length. The application points of the stabilizing forces $F_{W}$ and $F_{Q}$ were found to be at about $2 / 3$ of the height $h$ and halfheight from the top of the generic crack line [31], respectively. 
The actual resultant of the frictional resistances along each crack line can be evaluated as a weighted value in function of the crack inclination angle, i.e. [19]:

$$
F=F_{\max }\left(1-\frac{\beta}{\alpha_{b}}\right)
$$

where $\beta$ and $\alpha_{b}$ are the inclination of the generic crack line and of the half-unit shape, respectively.

\subsection{Non-linear kinematic approach}

The solution procedure to statically assess the seismic capacity of the examined rocking mechanisms is based on the kinematic approach of limit analysis and is first aimed at identifying the geometry of the moving macro-blocks (not known a priori) which minimizes the onset load factor. A subsequent pushover analysis is made by considering geometric non-linearity, that

211 is, by evaluating the load factor for varied kinematic configurations, as a function of the displacement of a control point.

212 By considering a varied configuration of the rocking corner represented by a finite rotation $\vartheta$ within the rotation plane (Figure

213 3), the virtual work performed by the resultant of the inertial forces $W$, applied on its centre of mass $\mathrm{G}$, can be expressed by 214 the relation:

$$
L_{W}=\lambda W z \phi-W x \phi
$$

215 where $\phi$ is the virtual rotation and $x y_{W}$ and $z_{W}$ are the horizontal and vertical distances of the rotated point $\mathrm{G}$ from the hinge, respectively. These, together with the angular position $\rho_{W}$ of the same point, are:

$$
x y_{W}=R_{W} \cos \left(\rho_{W}+\vartheta\right) ; \quad z_{W}=R_{W} \sin \left(\rho_{W}+\vartheta\right) ; \quad \rho_{W}=\tan ^{-1}\left(\frac{h_{w}}{s_{w}}\right)
$$

217 where $R_{W}$ is the radius vector connecting the pivot point $\mathrm{O}$ to the actual centre of mass $\mathrm{G}$.

218 The virtual work performed by the other horizontal forces $F_{1,2 l, 2 u}$ and component of $T_{s}$ parallel to OG can be expressed in a 219 similar way by only considering their vertical distances from the hinge (Figure 2). Thus, the load factor is simply derived from the application of the Virtual Work Principle as:

$$
\lambda=\frac{W x y_{W}+F_{1} z_{F 1}+F_{2 l} z_{F 2 l}+F_{2 u} z_{F 2 u}-\frac{\sqrt{2}}{2} T_{s}\left(a_{1}+a_{2}\right) z_{T}}{W z_{W}}
$$

221 where $a_{1}=\sin \gamma, a_{2}=\cos \gamma$ (Figure 2). It is easy to verify that $\lambda$ corresponds to the onset load factor for $\vartheta=0$ (Figure $3 \mathrm{a}$ ).

222 The assumed 3D configuration of the mechanism is defined by two unknown angles of crack (Figure 2a):

223 1) the inclination of the crack line with respect to the vertical Z-axis, say $\tan \beta_{1}$, for Wall 1 along Y-axis; 

axis.

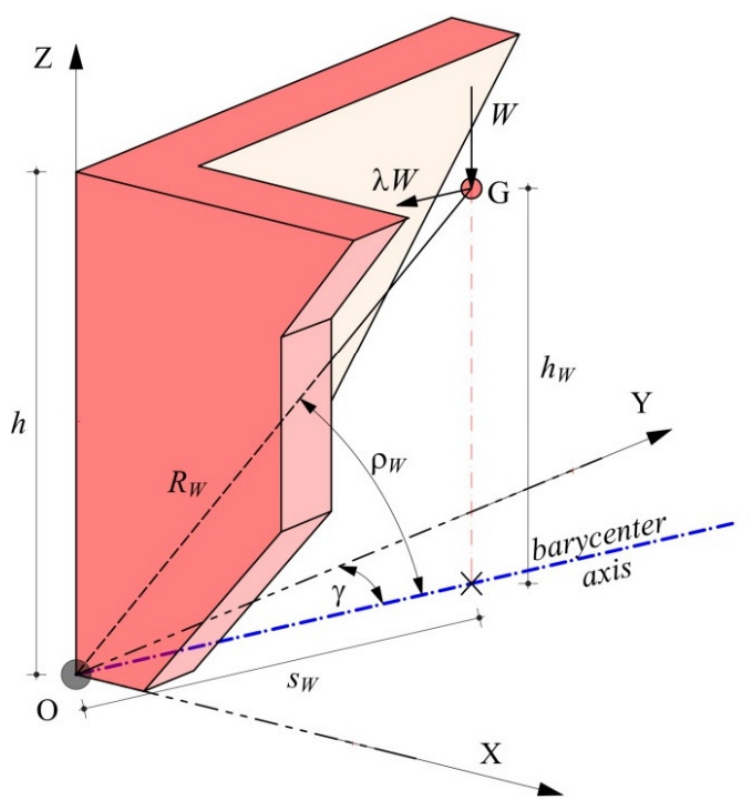

(a)

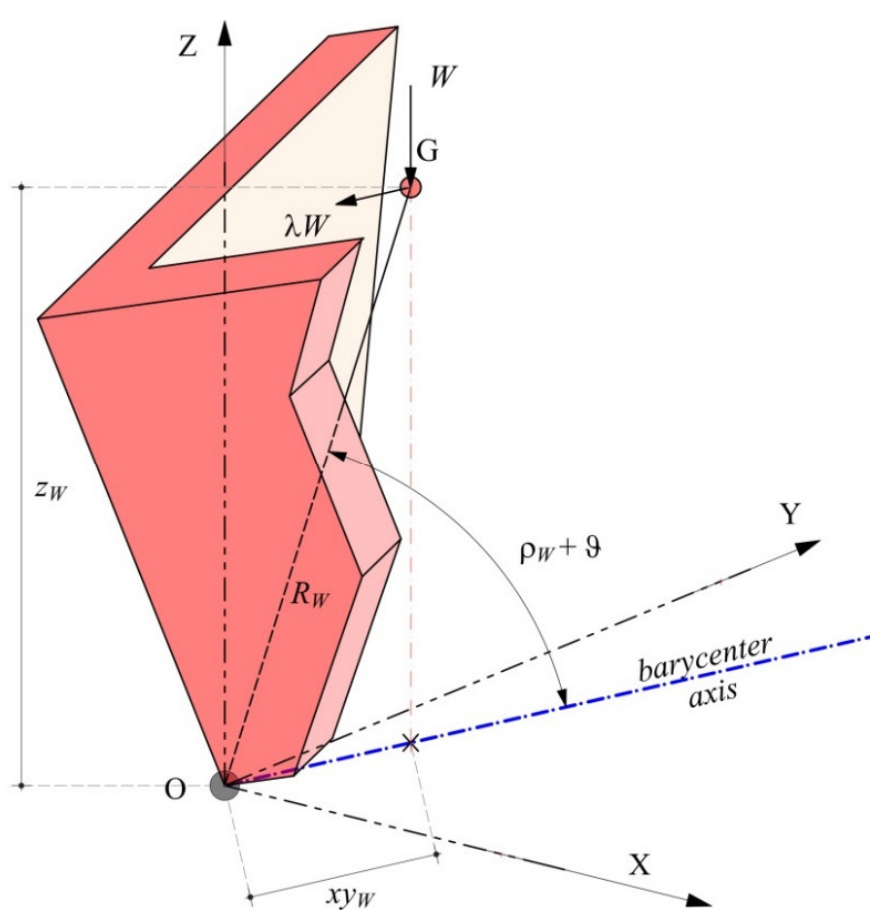

(b)

Figure 3 Initial (a) and varied (b) kinematic configurations of the corner.

The two unknown variables $\tan \beta_{1}$ and $\tan \beta_{2 u}$ that define the most likely failure configuration of the rocking corner are hence calculated through the condition of minimization of $\lambda$, under the following geometrical constrains:

$$
0 \leq \tan \beta_{1} \leq \tan \beta_{1 \max } ; \quad 0 \leq \tan \beta_{2 u} \leq \tan \beta_{2 u \max } \quad \text { with: } \tan \beta_{1 \max }=\tan \beta_{2 u \max }=\tan \alpha_{b}
$$

Pushover curves can then be performed from the static load factor. These curves are characterized by different phases of motion depending on the active contributions of links, till the ultimate equilibrium condition. A detailed description of the curves and the associated phases can be found in Section 4.2 where the model is applied to the masonry corner of the case study. The evolution of these phases in terms of the load factor and displacement is governed by the same Eq. (6) with updated coordinates of the application points, according to Eq. (5). The control point can be assumed as the same point for all phases, e.g. the centre of mass of the masonry portion only. Its displacement is affected by the variation of $x y_{W}$, i.e.:

$$
d_{C G}=s_{W}-x y_{W}
$$

The incremental analysis is extended till the control displacement for which $\lambda=0$. 
It is worth highlighting that, if active, the effect of friction gradually decreases after a certain displacement, due to the progressive detachment of the corner. The variation of the frictional forces can be represented by a non-linear function of the decreasing number of involved rows, similarly to the rocking façade, extensively described in [15]. The pushover curves can be constructed with reference to the forces and displacements belonging to the plane of rotation. Nevertheless, when the seismic capacity should be compared with the seismic demand represented in given directions, the curves can also be represented as their projections in different planes, as shown for the case study in Section 4.

\section{NON-LINEAR DYNAMIC ANALYSIS OF ROCKING CORNERS}

The non-linear dynamic analysis is the second method here proposed to assess the structural safety of masonry rigid blocks under earthquake ground motions. The two methods have in common the assumption that local mechanisms of masonry buildings can be idealized as kinematic chains of macro-block assemblages. The main difference with respect to the nonlinear static analysis lies in the fact that the dynamic analysis considers the evolution of motion over time, not neglecting the dynamic response that can be decisive especially for near-fault ground motions. The great potential of the dynamic analysis also consists in considering the energy dissipation over each impact, which is a phenomenon intrinsically connected to the dynamic motion of rigid objects. As opposed to the non-linear static analysis, which is based on the non-standard limit analysis when frictional resistances are taken into account, the way of considering seismic excitation is different. Indeed, in the nonlinear static analysis the horizontal static actions are assumed as a percentage of the gravity loads through a load factor applied to the centre of mass of each macro-block. In the dynamic analysis, the seismic input is assigned as acceleration time-history at the base of the block, and the response is obtained by the resolution of the equation of motion. In this way, the real seismic input is considered, not some intensity measures, such as Peak Ground Acceleration, Peak Ground Velocity or Displacement, Arias Intensity etc, which often cannot be significant or exhaustive for the problem under consideration. The main parameters describing the rigid block are the radius vector, a segment connecting the pivot point to the centre of walls, can be considered. When the rigid block under consideration is the rocking corner of a masonry building, these aspects can be considered in a similar way by selecting an appropriate prismatic block equivalent to the complex geometry of the corner. The equivalent ground motion has to be introduced by evaluating the dynamic properties of the whole building. 
By using the displacement-based method, pushover curves express the capacity of the masonry macro-block, which need to be combined with the acceleration displacement response spectra to allow the seismic verification. By contrast, the outcome computed with the dynamic analysis takes the form of a displacement time-history, whose peak corresponds to the demand. The condition of instability of the rocking motion is represented by the attainment of a rotation angle of $90^{\circ}$ (overturning condition).

\subsection{Rigid block model}

The rigid block model, rocking on a rigid base, follows a specific dynamics of motion, studied for the first time by Housner [4]. This model is intuitive and can be used for assessing the behaviour of masonry elements subjected to out-of-plane failures. The simplest form of the equation of motion, taken from the seminal Housner's work [4], is (Figure 4):

$$
I_{0} \ddot{\vartheta}+\operatorname{sgn}(\vartheta) m g R \sin (\alpha-\operatorname{sgn}(\vartheta) \vartheta)-m \ddot{u}_{g} R \cos (\alpha-\operatorname{sgn}(\vartheta) \vartheta)=0
$$

where $I_{\mathrm{O}}$ is the polar inertia moment with respect to the oscillation point $\mathrm{O}, I_{\mathrm{O}}=\frac{4}{3} m\left(h^{2}+t^{2}\right)=\frac{4}{3} m R^{2}$, and $\ddot{u}_{g}$ is the acceleration time-history. The model, with lumped mass $m$ concentrated in the center of mass of the block, does not consider either sliding nor bouncing, hypothesis that is acceptable when the slenderness of the block is greater than 3 [32]. The damping of the non-linear dynamic model is represented by the energy dissipation at each impact of the pivot points $\mathrm{O}$ or $\mathrm{O}$ ' on the ground. This is computed by reducing the velocity of rotation immediately after the impact through a reduction factor called “coefficient of restitution", function of the slenderness angle $\alpha$ [4].

As for the restraints, in general three configurations are possible, as shown in Figure 4:

a) free rocking block in bilateral or two-sided motion (2S), Figure 4a and Eq. (9);

b) block horizontally restrained by a concentrated spring with stiffness K, simulating a steel tie-rod (Figure 4b);

c) block horizontally restrained by a spring bed with stiffness K', simulating the transversal walls (Figure 4c). 
Among the three scenarios, the restrained ones are considered when dealing with masonry corners or masonry walls interacting with roofs [14]. In particular, for a realistic modelling, the unilateral or one-sided rocking (1S) should be preferred to the two-sided $(2 \mathrm{~S})$ one; in fact, for instance, if a steel tie-rod is the only active horizontal restraint, the effect of tying has to be assumed only when the tie-rod is in tension (Figure 4b), and therefore only in one direction of motion.

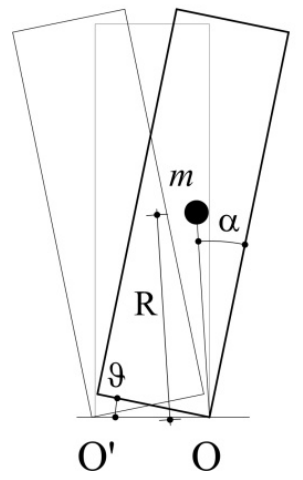

(a)

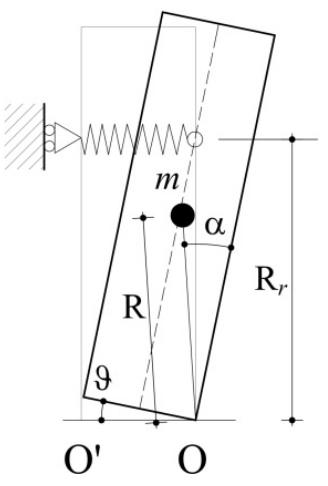

(b)

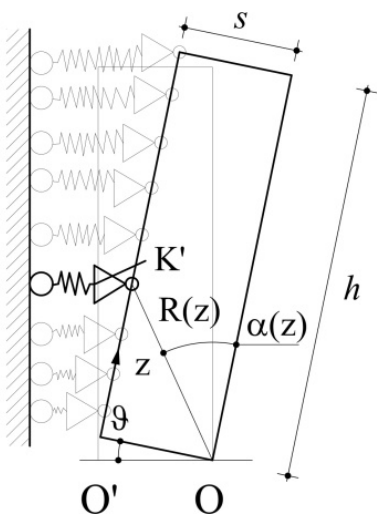

(c)

Figure 4 Housner's original block, bilateral or two-sided (2S) rotation (a), one-sided (1S) rotation of the block restrained by a single spring (b) and by a spring bed (c).

So, the activation of the horizontal restraints depends on the clockwise or counter-clockwise direction of the rocking motion. inherently non-linear even in the free condition due to the dependency of the terms in the equation of motion on trigonometric functions.

When the spring is compressed, one calls its stiffness $\mathrm{K}_{c}$ (single spring, in [F/L]) or $\mathrm{K}_{c}^{\prime}$ (spring bed, in $\left[\mathrm{F} / \mathrm{L}^{2}\right]$ ).

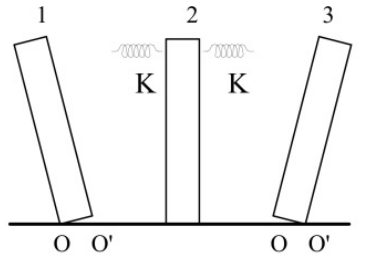

Same stiffness in

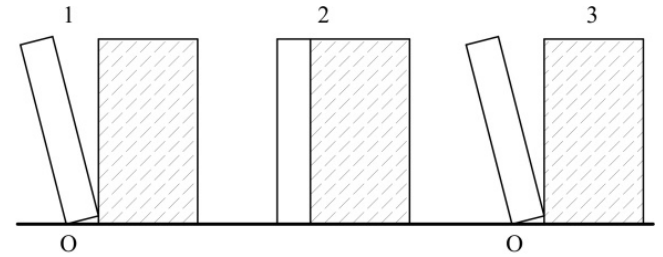

Different stiffness of tension/compression spring bed

(b)

Figure 5 Two-sided (2S) motion (a) and one-sided (1S) motion (b). 
The spring bed stiffness in compression $\mathrm{K}_{c}^{\prime}$ can be estimated with the following expression [26]:

$$
\mathrm{K}_{c}^{\prime}=\frac{\mathrm{Ex}_{\mathrm{X}} \mathrm{A}}{\mathrm{L} h}=\mathrm{E}_{\mathrm{x}} \frac{t_{t}}{\mathrm{~L}}
$$

where $\mathrm{E}_{\mathrm{x}}$ is the masonry elastic modulus in the horizontal direction, $t_{t}$ and $L$ respectively are the thickness and effective length of the transversal walls, whereas $\mathrm{A}=t_{t} h$ is their cross section. Eq. (10) is only valid if the spring bed is active along the whole height of the block $h$ (Figure 4c). In the opposite direction of rotation, the transversal walls can react by holding the rocking wall. Besides, although difficult to estimate, a spring bed in tension could be taken into account by considering the frictional resistances discussed in $\S 2.1$, in order to create a bridge with the kinematic analysis. A first attempt to define possible values of spring bed stiffness in tension $\mathrm{K}_{t}^{\prime}$ can be found in [33].

In summary, the smeared horizontal restraints representative of the transverse walls can be indicated with a stiffness $\mathrm{K}^{\prime}$, that can be equal either to $\mathrm{K}_{c}^{\prime}$ for the inward rotation (compressed walls) or to $\mathrm{K}_{t}^{\prime}$ in the outward rotation (walls in tensile state).

The steel tie-rods, if any, are supposed to be active only in tension and are modelled as individual springs. Their position is defined through a position coefficient $p=R_{r} / R$ (Figure 4b) [26], while $\alpha_{r}$ is the corresponding radius vector.

The complete equation of motion is:

$$
\begin{aligned}
& I_{0} \ddot{\vartheta}+\operatorname{sgn}(\vartheta) m g R \sin A_{\vartheta}+ \\
& \quad+\operatorname{sgn}(\vartheta) \mathrm{K} p^{2} R^{2} \cos A_{r, \vartheta}\left[\sin \alpha_{r}-\sin A_{r, \vartheta}\right]+\operatorname{sgn}(\vartheta) \mathrm{K}^{\prime} h\left(\bar{A}+\frac{\bar{B} h}{2}+\frac{\bar{C} h^{2}}{3}\right)-m \ddot{u}_{g} R \cos A_{\vartheta}=0
\end{aligned}
$$

where $A_{\vartheta}=\alpha-\operatorname{sgn}(\vartheta) \vartheta$ and $A_{r, \vartheta}=\alpha_{r}-\operatorname{sgn}(\vartheta) \vartheta$. The terms multiplying $\mathrm{K}^{\prime}$ are function of the rotation amplitude $\vartheta$ and of the wall thickness $s$ :

$$
\begin{aligned}
& \bar{A}=\operatorname{sgn}(\vartheta) s^{2} \sin \vartheta \cos \vartheta(1-\cos \vartheta) \\
& \bar{B}=s\left(\sin ^{2} \vartheta \cos \vartheta-\cos ^{3} \vartheta+\cos ^{2} \vartheta\right) \\
& \bar{C}=\operatorname{sgn}(\vartheta) \sin \vartheta \cos ^{2} \vartheta
\end{aligned}
$$

\subsection{Non-linear dynamic approach}

For the analysis of the rocking corner mechanism, the preliminary stage consists in defining an equivalent rectangular block through a specific equivalence criterion. This procedure has the aim of strongly simplifying the rocking analysis of the corner by solving Eq. (11) valid for a prismatic block and converting the 3D motion into an equivalent 2D behaviour.

Let us assume the general configuration displayed in Figure 6a,b, defined by the crack configuration described in $\S 2.2$ : tthe corner is composed by two intersecting walls, one has an opening and the other one is full and both walls are subjected to the 
roof overload. A straightforward method to take into account the roof loads regards the assumption of a system of lumped masses. Both walls are characterized by vertical uniformly distributed overloads and their resultants are punctual loads acting on A, B, C points. On point A, also the horizontal thrust of a strut, if any, can be considered. The steps required to find the equivalent perpendicular block are the identification of the centre of mass, the application points and entities of roof loads and horizontal restraints. The application points of the roof loads are considered as the current ones, without any modification, therefore some of them can fall within the equivalent block (as displayed in Figure 6c). As already introduced for the non-linear static model, two phases of motion can be distinguished, depending on the state of contact between roof and wall:

In phase 1 , the centre of mass $\mathrm{G}$ and the moment of inertia $I$ are obtained by the contribution of masses $m, m_{A}, m_{B}, m_{C}$. In phase 2, the contribution on the centre of mass $\mathrm{G}_{m}$ and on the moment of inertia $I_{m}$ are only due to the masonry portion, and therefore to the mass $m$. Phase 2 is reached once that a threshold horizontal displacement of the rocking corner is attained: by assuming that the roof stands in its own position, the contact between masonry corner and wall is not guaranteed anymore. Clearly, the equation of motion is updated considering the transition from phase 1 to phase 2, with a specific subroutine of the specifically developed MATLAB code. As described in $\S 2.1$, the inclination of the rotation axis $\omega$ is orthogonal to line OG during phase 1 (Figure 6a). The strategy to consider an equivalent prismatic block is to convert the motion around the $\omega$ axis into two components along the main building directions ( $\mathrm{X}$ and $\mathrm{Y}$ in Figure 6). The equivalent half-thickness of the wall, say in $\mathrm{X}$-direction (rotation around $\mathrm{Y}$ axis), is the X-coordinate of G. From it, the equivalence with the inertia moment corresponding to the real geometry of the corner gives the equivalent block height $h_{e q}$. 


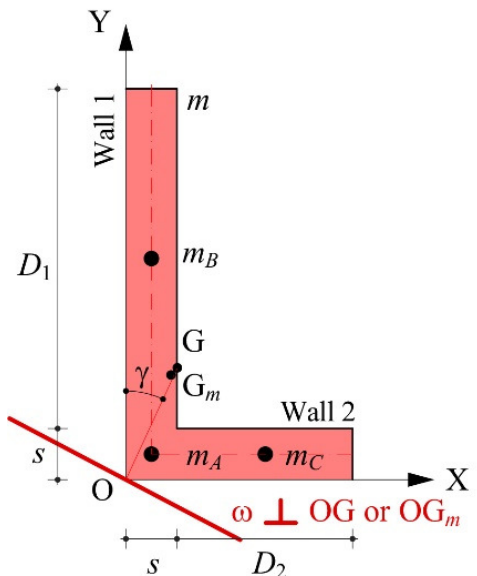

(a)

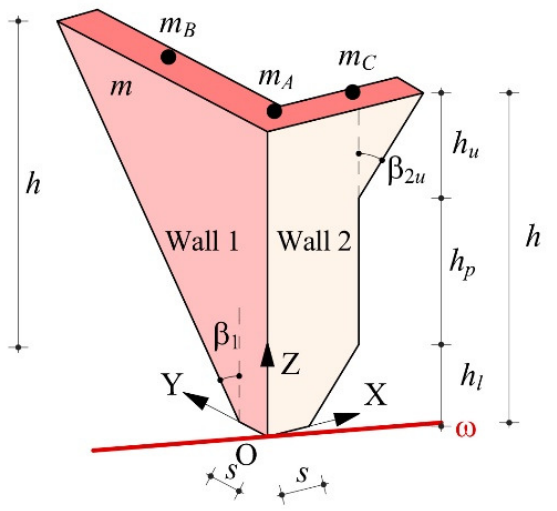

(b)

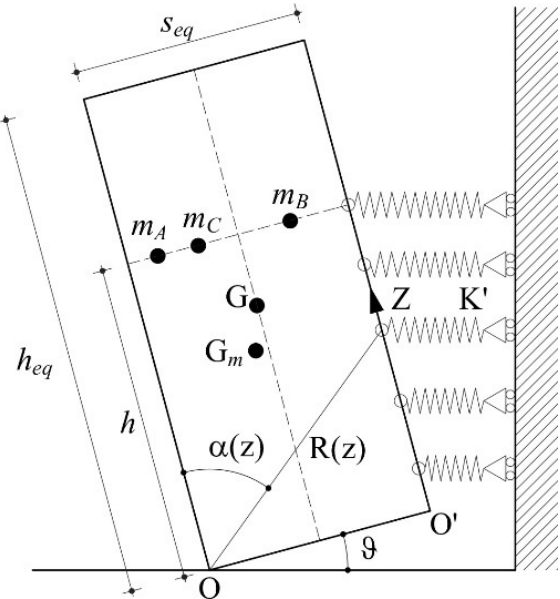

(c)

Figure 6 In-plan view of the corner mechanism (a), 3D view (b) and equivalent rectangular block (c) with the indication of the roof masses.

As for the boundary conditions, one-sided motion can be considered with a spring bed stiffness $\mathrm{K}^{\prime}$ representative of the transverse walls. In the inward direction and in the outward direction of rotation, respectively a compression and a tension spring bed stiffness can be defined according to what introduced in $\S 3.1$.

To correctly take into account these boundary conditions with respect to the rotation axis $\omega$, the stiffness has to be considered in the direction orthogonal to the rotation axis $\left(\mathrm{K}_{X}^{\prime}\right.$ and $\left.\mathrm{K}_{Y}^{\prime}\right)$ in such a way to include it in the equivalent mechanism (Figure 6c) [20]. More in detail, when the rotation axis is $X(Y)$, only the stiffness $K_{Y}^{\prime}\left(K_{X}^{\prime}\right)$ is considered. Again, the steel tie-rods, if present, can be considered with a spring of stiffness $\mathrm{K}$ acting in the actual application point. Another possible parameter to include in the equation of motion is the roof thrust $T_{s}$ if any, that can be computed with the method expressed in [14].

The final equation of the rocking corner mechanism is therefore:

$$
\begin{gathered}
I_{\omega} \ddot{\vartheta}+\sum_{i} \operatorname{sgn}(\vartheta) m_{i} g R_{i} \sin \hat{A}_{i}-\sum_{i} m_{i} R_{i} \cos \hat{A}_{i} \ddot{u}_{g} g+\operatorname{sgn}(\vartheta) \mathrm{K}^{\prime} h\left(\bar{A}+\frac{\bar{B} h}{2}+\frac{\bar{C} h^{2}}{3}\right)+ \\
+\operatorname{sgn}(\vartheta) \mathrm{K} R_{r}^{2} \cos \hat{A}_{r}\left[\sin \alpha_{r}-\sin \hat{A}_{r}\right]-T_{s} R_{r} \cos \hat{A}_{r}=0
\end{gathered}
$$




\subsection{The case study of a masonry corner collapsed during 2016-2017 Central Italy earthquakes}

The case study selected for the corner mechanism analysis is the primary school P. Capuzi in the municipality of Visso (Macerata, Central Italy), which was subjected to the seismic events of the 2016-17 Central Italy earthquake (Figure 7). The main damage occurred to the masonry building after the seismic shocks of August and October 2016 is the collapse of one corner in a typical out-of-plane mode due to improper connections between the walls and the timber roof. The analytical models described in the previous sections are hereby applied to this case study, to validate their reliability and suitability in the assessment of the seismic safety of the structure.

The building has a T-shape with four levels, three of them above ground (raised ground floor, first floor and attic) and a basement partially sub-grade. The load-bearing masonry walls extend upwards from the basement until the attic and are made of stone masonry (square rubble masonry type), with some parts in clay bricks. The hipped roof has a timber structure consisting of rafters and purlins that are supported by a system of beams or by the inner walls extending until the top of the roof. In correspondence of ridges and valleys, hip rafters are present. The information about geometry, structural configuration and seismic damage was supplied by the Italian Network of University Laboratories in Seismic Engineering (RELUIS) and the University of Genova, in charge of post-earthquake surveys [34]. This source also provided a detailed description of the

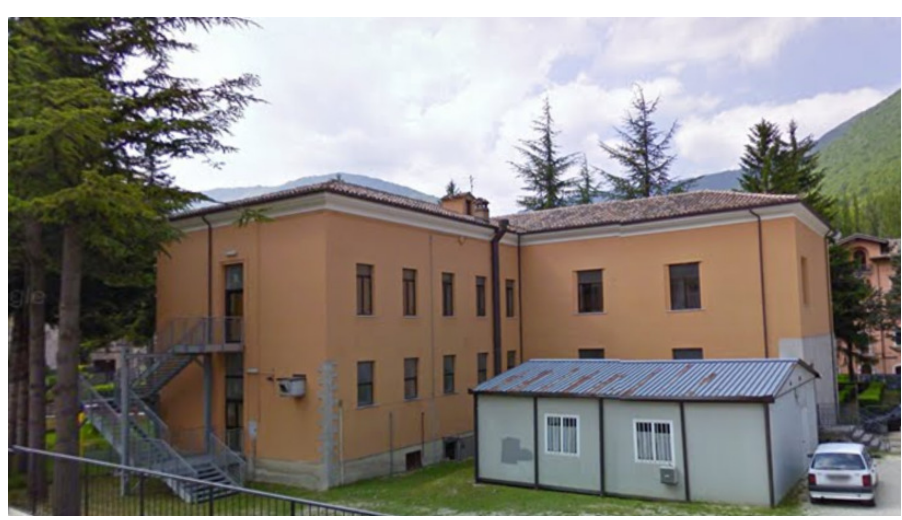

(a)

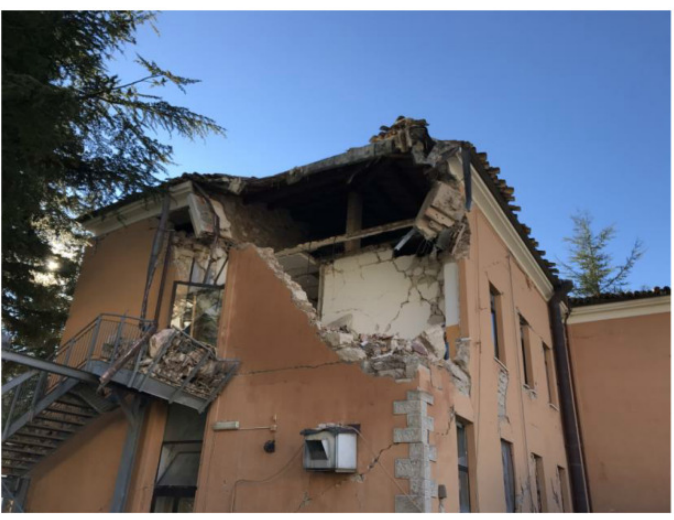

(b) 


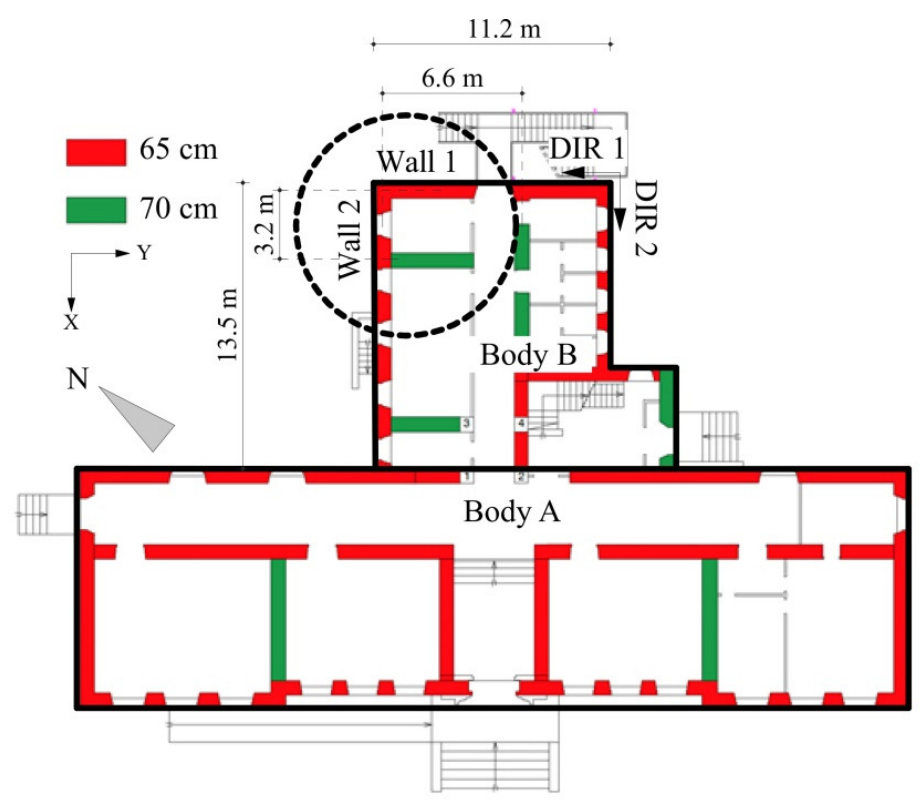

(c)

Figure 7 The P. Capuzi primary school in Visso (Macerata) before (a) and after (b) the 2016-17 Central Italy Earthquakes. Plan view of the first floor with a dashed circle indicating the corner failed (c) [34].

In order to analyze the corner failure, involving the upper level of the building (first floor and attic), it is important to highlight that the thrusting elements of the roof are the hip rafters sitting on the corners of the building along their bisector planes and rising to the central ridges (Figure 8); to each side of these hip rafters a number of purlins, with variable length, are framed parallel to the two intersecting walls, so defining a thrusting point load at about the centre of their intersection area, as described in detail in Appendix A. This means that the weight of the roof around the corner is transferred to the walls in major part through the hip rafter as a concentrated inclined load and in minor part (just the bottom strips of the roof) along the walls as uniformly distributed loads.

The masonry walls of the corner under study are made out of two outer layers of split stones and a rubble inner core, defining a transversal section with thickness $s$ of about $65 \mathrm{~cm}$. The average dimensions of the stone blocks are $l_{b}=30 \mathrm{~cm}$ and $h_{b}=15 \mathrm{~cm}$ (Figure 2c), while a conventional value of the thickness $s_{b}$ is herein assumed coincident with that related to the transversal section $\left(s_{b}=s\right)$. The blocks are arranged in a quite regular half-running bond pattern, allowing the adoption of the staggering ratio $\tan \alpha_{b}=l_{b} /\left(2 h_{b}\right)=1$, i.e. $\alpha_{b}=45^{\circ}$. The blocks are also assembled with mortar of good quality and provide sufficient transversal connections between the outer layers and the core, exhibiting therefore a good monolithic behavior. 
Table 1 reports the input data needed for the rocking analysis, together with those sketched in Figure 9. For the sake of simplicity, all overloads are collected in a unique uniformly distributed load applied on the vertical mid-plane of the walls. These overloads include weights transferred by the roof, concrete curb, low wall and horizontal diaphragm indicated in Figure 8b. In particular, the light diaphragm of the attic is assumed to be distributed $80 \%$ on Wall 2 and $20 \%$ on Wall 1 and $W_{s 0}$ is the weight of the concrete curb plus the low wall on the intersection of Walls 1 and 2.

407 To the end of the application of the two proposed models, the resultant of all the involved masses (the masses of the rocking macro-block and of the roof) was considered applied in the barycenter $G$ or $G_{m}$ (Figure 2 and Figure 6), depending on the considered phase of motion described in Section 3.2. $\mathrm{G}_{\text {or }} \mathrm{G}_{m}$ is a hypothetical point where all the involved masses may be assumed to be concentrated and where their weighted relative positions sum to zero. Details of calculation of the centre of mass coordinates for the collapsed corner are reported in Appendix B.

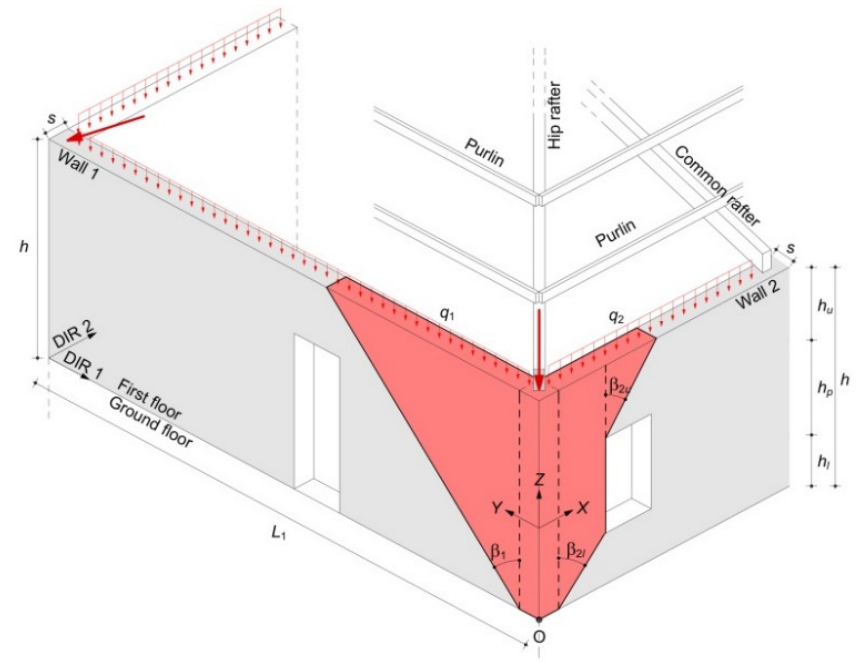

(a)

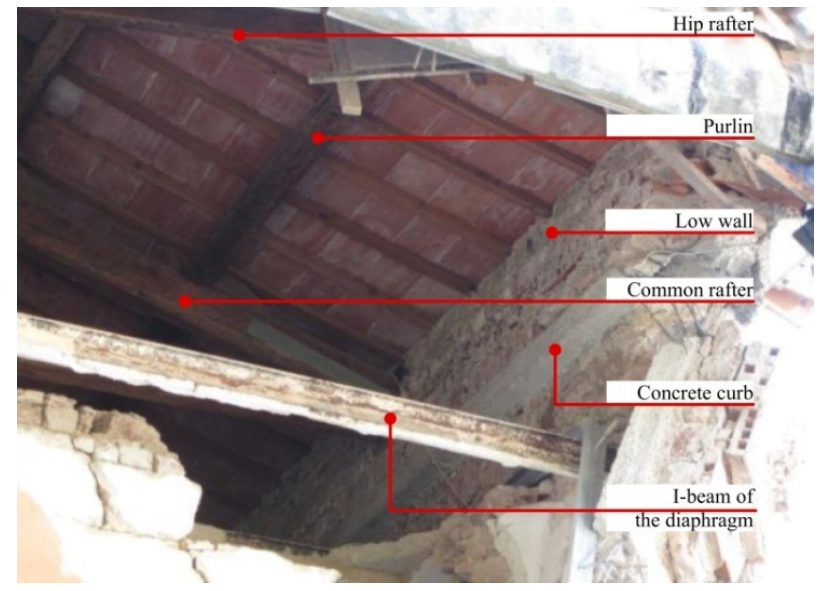

(b)

Figure 8 3D scheme of the school roof and corner (a) and details of other overloads on the walls (b). 


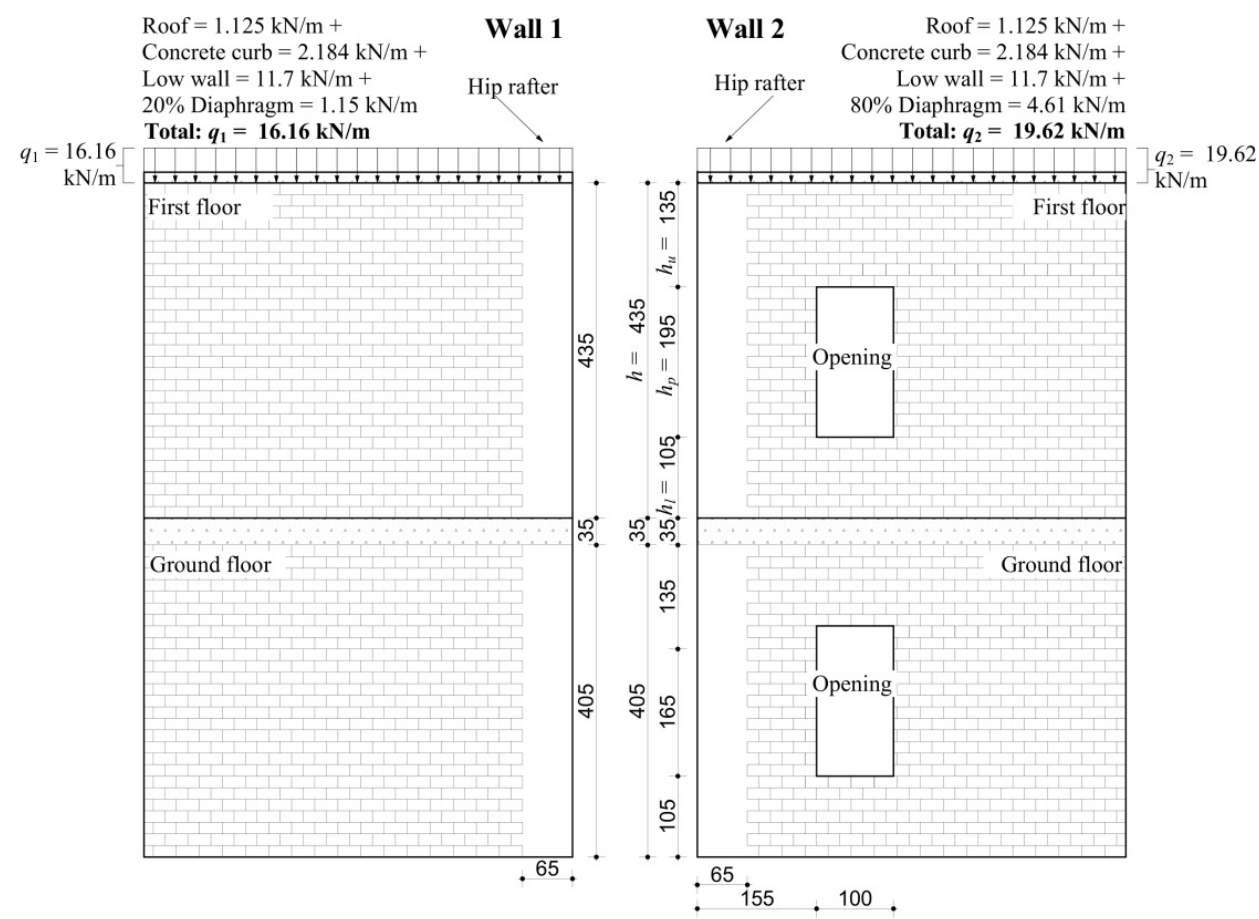

Figure 9 Wall 1 and wall 2 of the failed corner at the first floor, with dimensions in centimetres.

Table 1 Input data for the masonry corner analyzed with kinematic and dynamic analysis.

\begin{tabular}{|c|c|c|c|}
\hline \multicolumn{2}{|l|}{ Geometry } & \multicolumn{2}{|l|}{ Loadings } \\
\hline Height $[\mathrm{m}]$ & 4.35 & Specific weight of walls $\left[\mathrm{kN} / \mathrm{m}^{3}\right]$ & 21.00 \\
\hline Thickness of walls $(s)[\mathrm{m}]$ & 0.65 & Weight of half-unit $\left(W_{b}\right)[\mathrm{kN}]$ & 0.31 \\
\hline \multirow[t]{2}{*}{ Number of rows $(n)$} & 29 & Weight of the roof $\left(W_{r}\right)\left[\mathrm{kN} / \mathrm{m}^{2}\right]$ & 1.5 \\
\hline & & Overloads on Walls 1 and $2\left(q_{1}\right.$ and $\left.q_{2}\right)$ & 16.16 and 19.62 \\
\hline Block size $\left(l_{b} \times h_{b}\right)[\mathrm{m}]$ & $0.3 \times 0.15$ & {$[\mathrm{kN} / \mathrm{m}]$} & \\
\hline Inclination angle of the pitches $\left(\theta_{p}\right)\left[^{\circ}\right]$ & 21 & Overload on intersection of Walls $\left(W_{s 0}\right)[\mathrm{kN}]$ & 9 \\
\hline Inclination angle of the hip rafter $\left(\theta_{r}\right)\left[^{\circ}\right]$ & 15.19 & Gravity load due to the hip rafter $\left(W_{s}\right)[\mathrm{kN}]$ & 15.27 \\
\hline Tributary area of the hip rafter $\left(A_{p}\right)\left[\mathrm{m}^{2}\right]$ & 13.78 & Static thrust due to the hip rafter $\left(T_{s}\right)[\mathrm{kN}]$ & 1.87 \\
\hline \multicolumn{4}{|c|}{ Geometrical and mechanical properties of the equivalent rocking block } \\
\hline & around Y & around $\mathrm{X}$ & \\
\hline$s_{e q}[\mathrm{~m}]$ & 1.308 & 2.864 & \\
\hline$h_{e q}[\mathrm{~m}]$ & 6.199 & 6.342 & \\
\hline$R_{e q}[\mathrm{~m}]$ & 3.410 & 3.640 & \\
\hline
\end{tabular}




$\begin{array}{ccc}\alpha_{\text {eq }}[\mathrm{rad}] & 0.193 & 0.404 \\ \mathrm{~K}_{\mathrm{c}}{ }^{\prime}\left[\mathrm{N} / \mathrm{m}^{2}\right] & 1.57 \mathrm{E} 9 & 5.49 \mathrm{E} 8 \\ e[-] & 0.945 & 0.771\end{array}$

420

421

422

423

424

425

\subsubsection{The seismic input and limit states}

To analyze the seismic demand for the masonry corner under study, four seismic events of the 2016-2017 Central Italy earthquakes are taken into consideration. These are the first seismic shocks occurred on August $24^{\text {th }} 2016$ with magnitude $\mathrm{M}_{\mathrm{W}}=6.0$, when the failure mechanism activated, and the three sequences on October $26^{\text {th }}$ and $30^{\text {th }} 2016$ with magnitudes $\mathrm{M}_{\mathrm{W}}=5.4,5.9$ and 6.5 progressively, approximately when the corner totally collapsed [34].

Instead of the records on the ground, the analysis carried out in this paper is referred to the seismic inputs recorded by the biaxial accelerometer previously placed at the base of the first floor of the building, on the other corner of Body B (Figure 7c and Figure 8a). This is part of the system of accelerometers placed at different levels of the structure by the Seismic Observatory of Structures (OSS) [35] to permanently monitor the building. The acceleration and displacement time-histories obtained by the mentioned sensor for the selected seismic events allow characterization of the seismic input at the base of the corner as direct amplification of the corresponding ground motion.

In Table 2 some information about the four seismic events is reported, such as the distance of the school from epicentres, the Peak Ground Acceleration (PGA), Peak Floor Acceleration (PFA) and the amplification factor (PFA/PGA) obtained for the two horizontal components (Dir 1 and Dir 2) sketched in Figure 7c.

These events represent the seismic demands for the corner, herein named as displayed in the first column of the table. The data in this table show that the corner was subjected to significant values of horizontal motion; in particular, the highest values of horizontal PFA were recorded during the $\mathrm{M}_{\mathrm{w}}=6.5$ earthquake of October $30^{\text {th }}$, which were equal to $0.465 \mathrm{~g}$ and $0.682 \mathrm{~g}$ in the 1 (rotation around X, Figure 8a) and 2 (rotation around Y) directions, respectively. This means that the two PGAs of this seismic event were amplified 1.6 and 2.27 times on the first floor of the building, against the average amplification factors of 1.54 and 2.02 for Dir 1 and Dir 2, respectively.

Table 2 Peak ground and floor accelerations for the four 2016-17 Central Italy seismic events considered.

\begin{tabular}{|c|c|c|c|c|c|}
\hline Earthquake & Distance from epicentre $[\mathrm{km}]$ & Direction & $\begin{array}{c}\text { PGA } \\
{[\mathrm{g}]}\end{array}$ & PFA [g] & Amplification factor \\
\hline $2016 / 08 / 24 \mathrm{M}_{\mathrm{w}}=6.0$ & 28 & Dir 1 & 0.33 & 0.58 & 1.75 \\
\hline
\end{tabular}




\begin{tabular}{|c|c|c|c|c|c|}
\hline (Demand I-1,2) & & Dir 2 & 0.32 & 0.61 & 1.91 \\
\hline 2016/10/26_ $\mathrm{M}_{\mathrm{w}}=5.4$ & 7 & Dir 1 & 0.30 & 0.47 & 1.58 \\
\hline (Demand II-1,2) & & Dir 2 & 0.21 & 0.55 & 2.61 \\
\hline $2016 / 10 / 26 \mathrm{M}_{\mathrm{w}}=5.9$ & 4 & Dir 1 & 0.36 & 0.44 & 1.23 \\
\hline (Demand III-1,2) & & Dir 2 & 0.47 & 0.61 & 1.30 \\
\hline 2016/10/30_ $\mathrm{M}_{\mathrm{w}}=6.5$ & 10 & Dir 1 & 0.29 & 0.47 & 1.60 \\
\hline (Demand IV-1,2) & & Dir 2 & 0.30 & 0.68 & 2.27 \\
\hline
\end{tabular}

444 On the other hand, the capacity of the masonry corner should be referred to the equivalent non-linear Single Degree Of

445 Freedom (SDOF) system conventionally representing the motion of the corner in both static and dynamic analysis. In 446 particular, the capacity thresholds are herein represented by three limit states, i.e. LS0, LS1 and LS2, according to the threshold 447 values proposed by Giresini et al. [36]. The first one corresponds to the rocking initiation, which conventionally occurs when the PGA or PFA is greater than or equal to the minimum acceleration that causes rocking. The second one, LS1, is assumed to be a limit state for which the maximum displacement of the control point attains a value of $40 \%$ of its ultimate displacement $450 d_{0}^{*}$, the latter representing the instability displacement under quasi-static loading, also called static instability displacement. 451 This limit state can refer to a moderate rocking with some damages on the structures adjacent to the rocking corner itself. 452 Moreover, LS2 is representative of the near-collapse condition, assumed to be reached when the maximum displacement is $150 \%$ of $d^{*}$. It should be again noticed that, for a rocking wall system, the theoretical maximum limit of rotation is $90^{\circ}$ (overturning condition), and that the static limit can be overcome keeping the stability. However, to make comparable the two proposed approaches and for the sake of safety, in this work LS2 is chosen as the reference ultimate limit state. To summarize, for both models the three limit states correspond to the following capacity values at the floor level, respectively in terms of acceleration and displacement:

$$
\mathrm{LS} 0 \rightarrow \mathrm{PFA}_{\mathrm{C}}=\lambda_{0} \mathrm{~g} \quad \mathrm{LS} 1 \rightarrow d_{\mathrm{C} 1}^{*}=0.4 d_{0}^{*} \quad \mathrm{LS} 2 \rightarrow \quad d_{\mathrm{C} 2}^{*}=1.5 d_{0}^{*}
$$

where $\lambda_{0}$ is the initial load factor given by Eq. (6). In order to compare the results of the two proposed modelling approaches, the values of the parameters $\lambda_{0}$ and $d^{*}{ }_{0}$ in Eq. (14) are derived by the application of the static model and considered valid for the dynamic one, as developed in the following sections for the case under study. The only slight difference is in the PFA which for the static model takes into account the rate of the total mass $e^{*}$ described in Section 4.2.

462 The seismic assessment of the rocking masonry corners is thus evaluated by a safety index $\zeta$ summarizing the comparison between the expected seismic capacity and demand, with reference to the three LS0, LS1 and LS2 limit states, i.e.: 


$$
\zeta_{\mathrm{LS} 0}=\frac{\mathrm{PFA}_{\mathrm{C}}}{\mathrm{PFA}_{\mathrm{D}}} \quad \zeta_{\mathrm{LS} 1}=d_{\mathrm{C} 1}^{*} / d_{\mathrm{D}}^{*} \quad \zeta_{\mathrm{LS} 2}=d_{\mathrm{C} 2}^{*} / d_{\mathrm{D}}^{*}
$$

where the subscript $\mathrm{D}$ indicates the demand. The verification is satisfied if the indexes are greater than unity.

It is worth highlighting that the evaluation of the seismic demand for LS1 and LS2 in terms of displacements is performed by following different procedures for the two modelling approaches. In fact, while the displacement demand for the dynamic model is a direct result of the dynamic equations, the static model requires the superimposition of the capacity curve with the demand ADRS, as described in the following section.

\subsection{Application of the non-linear static model}

The first step to assess the seismic capacity of the corner under study is the definition of the geometry of the failing wedge by means of the limit analysis procedure described in Section 2, i.e. by minimizing the load factor expressed by Eq. (6) with respect to the two unknown angles of crack on the two intersecting walls. As highlithed in Figure B.1 and Table B.1 of Appendix B, the geometric parameters $C_{1}$ and $C_{2}$ of the failing wedge are strictly related to these angles in terms of tan $\beta_{1}$ and $\tan \beta_{2 u}$, respectively, while frictional resistances depend on these angles through Eq. (3).

The procedure is developed for spreadsheet and a multipurpose mathematical programming solver is used to solve the problem of optimum. By assuming the friction coefficient $f=0.6$, as suitable for stone masonry walls [37-39], the result of the minimum load factor is $\lambda=0.464$ and the resulting geometry pattern of the moving corner is a wedge characterized by the two angles of crack $\beta_{1}$ and $\beta_{2 u}$ equal to their maximum value given by the half-unit shape, i.e. $\alpha_{b}=45^{\circ}$ (Figure $2 \mathrm{c}$ ). This means zero frictional resistances provided by Eq. (3) and only activation of pure rotation.

This result is in very good agreement with the actual collapse pattern observed in Figure $7 \mathrm{~b}$, where it is evident that the presence of a window in Wall 2 strongly influences the development of the cracks. In fact, these tend to localize near the vertexes of the opening, while a greater portion of Wall 1 is involved. By contrast, the opening in Wall 1 does not affect the configuration of the rocking wedge because quite far from the corner and the inclination of the crack line results to be at its maximum value $\left(\beta_{1}=\alpha_{b}\right)$.

The values of the forces defining the minimum load factor of Eq. (6) are summarized in Table 3, where $W$ is the sum of all the involved weights reported in Table B.1 of Appendix B. These can also be distinguished in the weight of the failing masonry corner $\left(W_{m}\right)$ and that of the roof $\left(W_{q}\right)$. 
Table 3 Forces defining the minimum load factor for the failing masonry corner under study.

\begin{tabular}{cccc}
\hline & Value & Horizontal lever arm $(x y)$ & Vertical lever arm $(z)$ \\
Forces & {$[\mathrm{kN}]$} & {$[\mathrm{m}]$} & {$[\mathrm{m}]$} \\
\hline Weight of the failing masonry corner $\left(W_{m}\right)$ & 227.17 & 1.45 & 2.73 \\
Weight of the roof $\left(W_{q}\right)$ & 138.73 & 1.57 & 3.35 \\
Resultant of gravity loads $(W)$ & 365.9 & - & - \\
Fricitional resistances $\left(F_{i}\right)$ & 0 & - & 4.35 \\
Static thrust $\left(T_{s}\right)$ & 1.87 & & \\
\hline
\end{tabular}

491

492 Besides, as already stated in $\S 3.2$, the evolution of the motion is characterized by two distinct phases, depending on the contact between roof and wall:

- phase 1: the corner rotates till the complete unthreading of the roof;

- $\quad$ phase 2: the corner rocks without the contribution of the roof loads.

In phase 1, the centre of mass $\mathrm{G}$ is obtained with the contribution of all the masses involved, as detailed in Appendix B. Its coordinates are derived by Eq. (B.1) to be $x_{\mathrm{G}}=0.65, y_{\mathrm{G}}=1.43$ and $z_{\mathrm{G}}=3.35$, while the vertical plane of rotation results to be inclined of $\gamma=24.54^{\circ}$ with respect to the YZ-plane, according to Eq. (B.2). In phase 2, the new centre of mass $\mathrm{G}_{m}$ is only related to the masonry portion (Figure 6), with new coordinates $x_{\mathrm{G} m}=0.57, y_{\mathrm{G} m}=1.33$ and $z_{\mathrm{G} m}=2.73$, while $\gamma_{m}=23.24^{\circ}$ from Eq. (B.3).

However, the pushover curve displayed in Figure 10 is constructed with reference to the control point which is the centre of mass $\mathrm{G}_{m}$ accounting for the masonry portion only (phase 2). This curve is obtained using Eqs. (6) and (8) for increasing angle of rotation $\vartheta$ (Figure 3). Moreover, it is referred to the capacity along the plane of rotation that is orthogonal to the rotation axis $\omega$ (Figure 2). As shown in Figure 10, the transition from phase 1 to phase 2 is expected to occur at the displacement $d_{G 0}=0.49 \mathrm{~m}$, calculated using Eq. (8). 


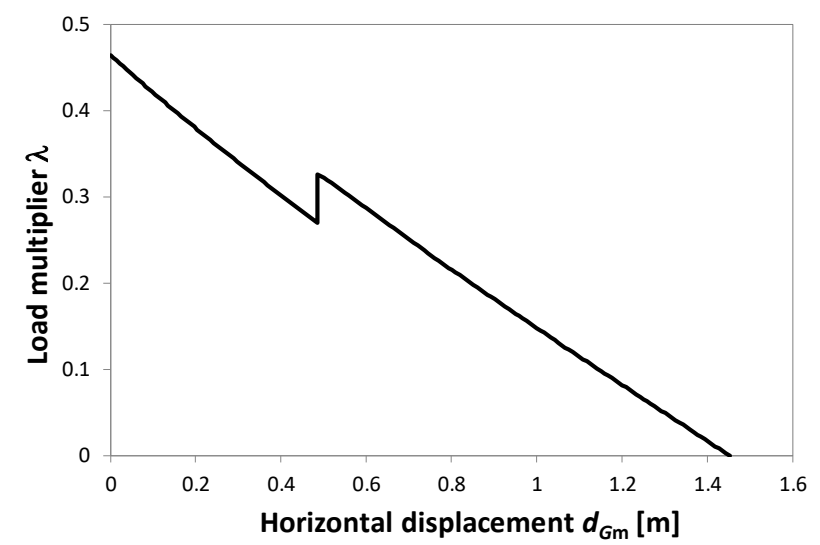

Figure 10 Pushover curve of the collapsed corner in the masonry school building under study.

509 According to the Capacity Spectrum Method $[23,40]$, the capacity curve of the equivalent non-linear SDOF system is derived

510 from the pushover curve by assuming:

$$
a^{*}=\frac{\lambda g}{e^{*}} \quad d_{G m}^{*}=\Gamma d_{G m}
$$

511 where, $e^{*}$ is the rate of the total mass that participates to the rocking mechanism and $\Gamma$ is the transformation factor of the displacements. Being $\delta_{x, j}$ the virtual horizontal displacement of the $j$-th lamping mass, the two introduced factors are:

$$
e^{*}=\frac{\left(\sum_{j} W_{j} \delta_{x, j}\right)^{2}}{\sum_{j} W_{j} \sum_{j} W_{j} \delta_{x, j}^{2}} \quad \Gamma=\frac{\sum_{j} W_{j} \delta_{x, j}^{2}}{\delta_{x, G m} \sum_{j} W_{j} \delta_{x, j}}
$$

513 which assume different values for each of the two phases of motion. In fact, taking into account the values in Table 3 , these

514 factors are equal to unity when only the masonry portion is involved in the mechanism (phase 2 ), while $e^{*}=0.95$ and $\Gamma=1.29$

515 for the whole phase 1, as reported in Table 4.

516

Table 4 Factors to define the SDOF system in the two phases of motion.

\begin{tabular}{ccc}
\hline Factors (Eq. (17)) & Phase 1 & Phase 2 \\
\hline$e^{*}=\frac{\left(W_{m} z_{m}+W_{q} z_{q}\right)^{2}}{W\left(W_{m} z_{m}^{2}+W_{q} z_{q}^{2}\right)}$ & 0.95 & 1 \\
$\Gamma=\frac{W_{m} z_{m}^{2}+W_{q} z_{q}^{2}}{z_{m}\left(W_{m} z_{m}+W_{q} z_{q}\right)}$ & 1.29 & 1 \\
\hline
\end{tabular}


The seismic capacity and demand of the static model are then superimposed in terms of acceleration $a^{*}$ and $\operatorname{displacement} d^{*}{ }_{G m}$ of the equivalent non-linear SDOF system, with reference to the two directions of the available seismic inputs recorded by the bi-axial accelerometer (Figure 11). To this aim, the capacity is represented by the two components of acceleration and displacement along the Directions 1 and 2, given by the following expressions:

$$
\begin{array}{lcc}
a_{1}^{*}=a^{*} \cos \gamma & d_{1, G m}^{*}=d_{G m}^{*} \cos \gamma & \text { for Dir 1 } \\
a_{2}^{*}=a^{*} \sin \gamma_{m} & d_{2, G m}^{*}=d_{G m}^{*} \sin \gamma_{m} & \text { for Dir 2 }
\end{array}
$$

The resulting capacity curves obtained using Eq. (16) for increasing angle of rotation $\vartheta$ (Figure 3 ) are almost straight lines, with different initial accelerations $\left(a_{0}^{*}\right)$ and final displacements $\left(d^{*}{ }_{0}\right)$. In fact, $a_{0,1}^{*}=4.37 \mathrm{~m} / \mathrm{s}^{2}$ and $d^{*}{ }_{0,1}=1.33 \mathrm{~m}$ for DIR 1 , while $a_{0,2}^{*}=2 \mathrm{~m} / \mathrm{s}^{2}$ and $d_{0,2}^{*}=0.57 \mathrm{~m}$ for DIR 2 . The change from phase 1 to phase 2 is also indicated in the figures for both directions.

On the other hand, the demand of the available seismic inputs is expressed in terms of overdamped elastic ADRS, by applying a damping correction factor $\eta$, like the one proposed by Eurocode 8 [41]:

$$
\eta(T)=\sqrt{\frac{10}{5+\xi(T)}}
$$

where an equivalent viscous damping $\xi=5 \%(\eta=1)$ is assumed.

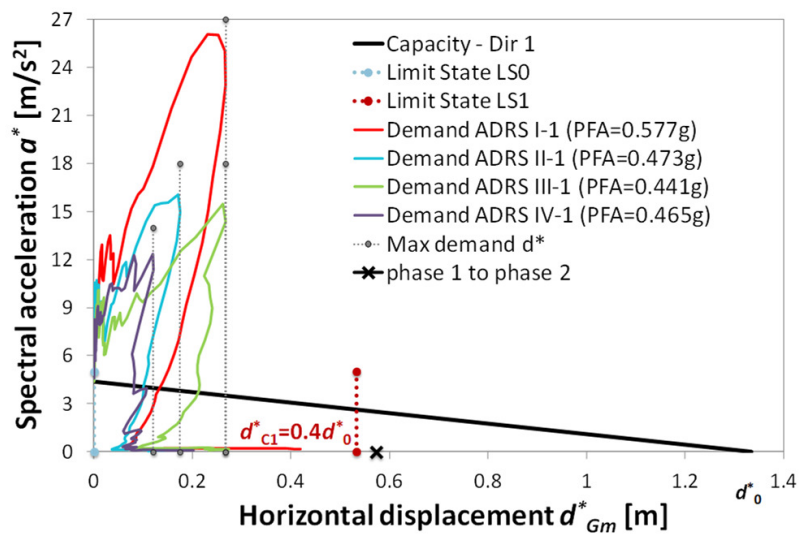

(a)

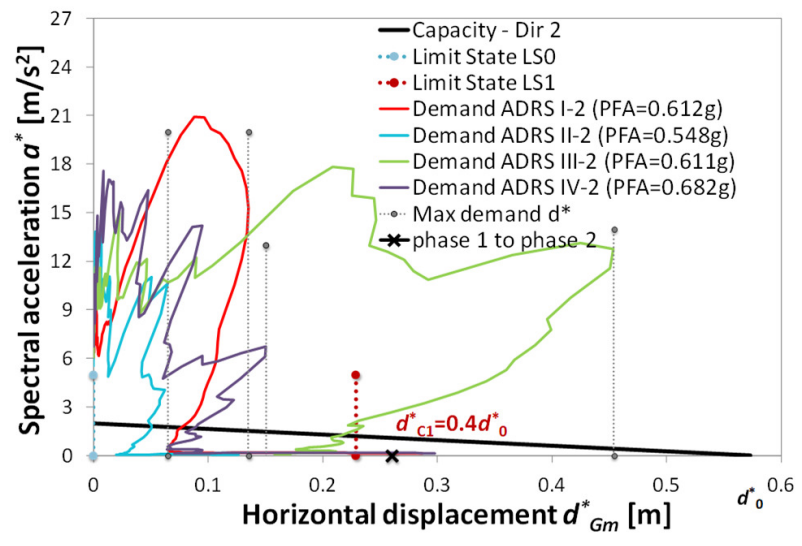

(b)

Figure 11 Evaluation of the displacement demand of the rocking corner by means of the non-linear static model, for

Direction 1 (a) and Direction 2 (b).

The capacity thresholds are represented by the three LS0, LS1 and LS2 limit states expressed by Eq. (14), which are the same for the two presented models. It is worth highlighting that the LS1 limit state is close to the first threshold horizontal displacement (phase 1 to phase 2) for both directions, corresponding to the complete unthreading of the roof. This means that 
for this case study the LS1 limit state substantially represents this threshold. The three limit states of Eq. (14) are reported in Table 5 for the direction of the plane of rotation, which is orthogonal to $\omega$, and for DIR 1 and DIR 2 as functions of the angle $\gamma$ or $\gamma_{m}$, according to Eq. (18).

From Figure 11 and Table 5, it is first evident that the most vulnerable direction is DIR 2 with the lowest capacity both in terms of acceleration and displacement and with most demanding input represented by the $\mathrm{M}_{\mathrm{w}}=5.9$ earthquake of October $26^{\text {th }}$ (Table 2). This first result is in perfect agreement with the actual collapse occurred just after this input, as clearly indicated by the survey reports $[34,42]$.

Table 5 Seismic capacity for the three limit states LS0 (mechanism activation), LS1 (moderate rocking) and LS2

(near-collapse).

\begin{tabular}{lccc}
\hline & LS0 - PFA $[\mathrm{g}]$ & LS1 $-d^{*}{ }_{\mathrm{C} 1}[\mathrm{~m}]$ & $\mathrm{LS} 2-d_{\mathrm{C} 2}^{*}[\mathrm{~m}]$ \\
\hline $\mathrm{DIR} \perp_{\omega}$ & 0.49 & 0.58 & 2.18 \\
$\mathrm{DIR} 1$ & 0.45 & 0.53 & 2.00 \\
$\mathrm{DIR} 2$ & 0.20 & 0.23 & 0.86 \\
\hline
\end{tabular}

\subsection{Application of the non-linear dynamic model}

The geometry of the rocking corner defined by the non-linear static analysis is assumed to be the same for the application of non-linear dynamic analysis. The validity of this assumption can be found in the parametric analysis performed in [Giresini et. Al. 2019 che è l'attuale citazione [20] One-sided rocking motion...].

Based on this geometry, the rocking analysis is performed by considering an equivalent prismatic block characterized by an equivalent radius vector $R_{e q}$, between $3.41 \mathrm{~m}$ and $3.64 \mathrm{~m}$ and slenderness angle $\alpha$ between 0.193 and 0.404 according to the rotation axis (Table 1). The corresponding coefficients of restitution, calculated according to Housner [4], are between 0.77 and 0.95 . The mechanical parameters associated with the boundary conditions are the compression spring bed stiffness around $\mathrm{X}$ and $\mathrm{Y}(\S 3.2)$ that simulate the transverse walls. The larger value is for the compressive stiffness when the inward rotation is around $\mathrm{Y}$, equal to $1.57 \mathrm{E} 9 \mathrm{~N} / \mathrm{m}^{2}$, greater than the orthogonal value of $5.49 \mathrm{E} 8 \mathrm{~N} / \mathrm{m}^{2}$ [20]. This is due to the fact that the effective length of the transverse wall in X direction is lower because of the presence of the opening. Moreover, null tension spring bed stiffness is assumed in accordance with the non-activation of frictional resistances obtained by the static analysis. 
However, this assumption may imply more rebound effects in the free direction of rotation (e.g. in negative Y direction if the rotation around $\mathrm{X}$ axis is assumed, Figure 6a), which could indeed cause the overturning of the rigid block [25]. The results of the rocking analyses are reported in Table 6 for each limit state only for the most vulnerable direction DIR 2 , which is the most vulnerable also in the rocking analysis with the higher demand. It is important to notice that the peak displacement caused by the earthquake of October $26^{\text {th }}$ - that actually caused the collapse - is the greatest and equal to $36 \mathrm{~cm}$. However, it should be also pointed out that the numerical analysis did not gather the overturning of the block with this seismic record (namely, it did not reach a rotation of $90^{\circ}$ in the time-history). The second most vulnerable earthquake is the first of seismic swarm, the $\mathrm{M}_{\mathrm{w}}=6.0$ earthquake of August $24^{\text {th }}$, that indeed probably formed the cracks during the ground motion but did not determine the instability of the corner. In this case, the peak displacement suggested by the rocking analysis is $29 \mathrm{~cm}$, quite close to the previous value, although the PGA is significantly lower $(0.32 \mathrm{~g}$ against $0.47 \mathrm{~g})$ and the epicentre was further away (29 km against $4 \mathrm{~km})$, as shown in Table 2. It is again pointed out that, for the dynamic analysis outcomes, the demand is the same for limit states LS1 and LS2, since the demand is defined as the peak of the displacement time-history, which is unique for each seismic record.

Table 6 Seismic demand for the three limit states LS0 (mechanism activation), LS1 (moderate rocking) and LS2

$$
\text { (near-collapse). }
$$

\begin{tabular}{lccc} 
& LS0 - PFAD $[\mathrm{g}]$ & LS1 $-d_{D}^{*}[\mathrm{~m}]$ & LS2 $-d_{D} *[\mathrm{~m}]$ \\
\hline Demand I-2 & 0.61 & 0.29 & 0.29 \\
Demand II-2 & 0.55 & 0.01 & 0.01 \\
Demand III-2 & 0.61 & 0.36 & 0.36 \\
Demand IV-2 & 0.68 & 0.07 & 0.07 \\
\hline
\end{tabular}

\section{COMPARISONS BETWEEN THE TWO PROPOSED MODELS}

579 The results of the non-linear static and dynamic analyses, here only referred to the most vulnerable DIR 2, can be discussed 580 in terms of a) limit states, b) seismic input and c) seismic safety index, as summarized in Table 7.

581 From these results it is evident that the static model proves to be always more conservative than the dynamic model for the onset of the mechanism and for the other limit states, with the exception of LS1 and LS2 of the Demand I-2, e.g. the Mw $=6.0$ earthquake of August $24^{\text {th }}$. This is the first earthquake of the seismic swarm that most likely caused the formation of the 
diagonal cracks in the masonry walls and therefore the corner geometry. The results confirm that both models can capture the activation of the motion (LS0) occurred for this input, since the safety factors are much less than unity in both directions. However, this earthquake had a low seismic demand in terms of displacement and could not cause the collapse of the corner (Figure 11).

Even the subsequent $\mathrm{M}_{\mathrm{w}}=5.4$ earthquake of October $26^{\text {th }}$ (Demand II-2) with its lowest demand but greater amplification factor (Table 2) could only add more damage to the corner without causing its collapse. Instead, the limit state of moderate rocking (LS1) was reached for the second main shock of October $26^{\text {th }}$ (Demand III-2) and, due to the cumulative damage, the corner eventually collapsed. The predictions of the two models are in good agreement with this event, because the safety factors for LS2 state slightly greater than unity do neglect the progressive damaged actually undergone by the masonry structure. As for the comparison of seismic demands, one can notice that between static and dynamic models the first one is not affected by the PGV value of the seismic record, which is instead a relevant seismic intensity measure influencing the stability of an oscillating block. For this reason, it can be observed from Table 7 that Demand I-2 implies a greater seismic demand for the dynamic model than that for the static model, since its PGV is of medium-high intensity (PGV=56 cm/s). In addition, the seismic demands are greater for higher PGA values (comparisons between Demands I-2 and II-2 and between Demands III-2 and IV-2 in Table 2).

Comparing the safety indexes of the outcomes of the two approaches, one can observe that the results of the static analysis are "smoother", with values close to unity (with the exception of $\zeta=13.26$ for Demand II-2). By contrast, when the block is stable for the rocking analysis, due to its strongly reduced motion, the demand, that is the peak response, may be so low that the safety index becomes extremely high (e.g. 22.91, 85.91 for Demand II-2). However, the good predictions of the onset and overturning of the rocking masonry corner selected as a real case study, allow considering the two presented approaches in static and dynamic fields as reliable and efficient modelling strategies, capable to be easily extended to any kind of local failure in masonry buildings and useful to practitioners as well.

Table 7 Seismic demands and safety indexes for LS0, LS1 and LS2 in DIR 2.

\begin{tabular}{|c|c|c|c|c|c|}
\cline { 3 - 6 } \multicolumn{2}{c|}{} & \multicolumn{2}{c|}{ Seismic Demand } & \multicolumn{2}{c|}{ Seismic safety index $\zeta$} \\
\cline { 3 - 6 } \multicolumn{2}{c|}{} & Static Model & Dynamic Model & Static Model & Dynamic Model \\
\hline \multirow{2}{*}{ Demand I-2 } & LS0 [g] & 0.62 & 0.61 & 0.33 & 0.33 \\
\cline { 2 - 6 } & LS1 [m] & 0.14 & 0.29 & 1.70 & 0.79 \\
\hline
\end{tabular}




\begin{tabular}{|c|c|c|c|c|c|} 
& LS2 [m] & 0.14 & 0.29 & 6.36 & 2.96 \\
\hline \multirow{5}{*}{ Demand II-2 } & LS0 [g] & 0.56 & 0.55 & 0.36 & 0.37 \\
\cline { 2 - 6 } & LS1 [m] & 0.06 & 0.01 & 3.54 & 22.91 \\
\cline { 2 - 6 } & LS2 [m] & 0.06 & 0.01 & 13.26 & 85.91 \\
\hline \multirow{3}{*}{ Demand III-2 } & LS0 [g] & 0.62 & 0.61 & 0.33 & 0.33 \\
\cline { 2 - 6 } & LS1 [m] & 0.45 & 0.36 & 0.50 & 0.64 \\
\cline { 2 - 6 } & LS2 [m] & 0.45 & 0.36 & 1.89 & 2.39 \\
\hline \multirow{3}{*}{ Demand IV-2 } & LS0 [g] & 0.69 & 0.68 & 0.30 & 0.30 \\
\cline { 2 - 6 } & LS1 [m] & 0.15 & 0.07 & 1.52 & 3.27 \\
\cline { 2 - 6 } & LS2 [m] & 0.15 & 0.07 & 5.71 & 12.27 \\
\hline
\end{tabular}

\section{CONCLUSIONS}

610 This work presented the analysis of a typical out-of-plane failure mode in masonry buildings with two complementary 611 approaches: the non-linear static and the non-linear dynamic methods. The first one, considering the frictional resistances, is 612 able to predict with a high degree of precision the collapse load factor that activates the incipient mechanism and the capacity 613 curve in terms of displacements, to compare with the seismic demand. The non-linear dynamic analysis considers the 614 evolution of one-sided motion over time by taking into account the influence of transverse walls and energy dissipation under 615 the real seismic record. The two methodologies have been here specialized for considering the corner mechanism, very

616 frequent in masonry buildings subjected to earthquakes especially when the interaction with a thrusting roof is present.

617 The seismic assessment of a corner mechanism formed in a school building, subjected to the seismic swarm occurred in 618 Central Italy in 2016-2017, was carried out with reference to three limit states, i.e. rocking initiation (LS0), moderate rocking 619 (LS1) and near-collapse (LS2) conditions, being LS0 and LS1 representative of serviceability limit states, while LS2 was 620 considered as an ultimate limit state.

621 The comparison of results showed a good agreement of the models with the real behaviour of the rocking structure and with each other, even if the static model appears to be more conservative than the dynamic model. In particular, both models were capable to provide a reliable prediction both of the activation of motion for the corner and of its complete collapse. The latter occurred during the most demanding earthquake in terms of displacement of the seismic events of the 2016-17 Central Italy sequence. 

their potential and suitability to be applied to any kind of masonry structural or non-structural element with reference to different geometries, constraints and performance levels.

\section{ACKNOWLEDGMENTS}

631 The authors acknowledge the sponsorship of the Italian Civil Protection, through the RELUIS Project - Line: Masonry 632 Structures. In order to define the static action that the hip rafter exerts on the intersecting walls, the isostatic scheme shown in Figure A.1 is adopted. According to this scheme, it is assumed that the action $R_{b}$ provided by the ridge beam on the hip rafter is oriented orthogonally to it. It is worth noting that, although this assumption is a great simplification of the more complex connection, it represents a reliable condition between the bounding vertical and horizontal orientations of the ridge support. A linear distributed load, increasing towards the corner, represents the vertical load transferred by the purlins to the hip rafter. The resultant of this load is $Q_{p}=\left(A_{p} \times W_{r}\right) / \cos \theta_{p}$, being $A_{p}$ and $W_{r}$ the tributary area and the weight of a square meter of the roof,

641 respectively, and $\theta_{p}$ the inclination angle of the pitches.

642 Hence, the horizontal and vertical components of the reaction of the hip rafter are respectively $T_{s}$ and $W_{s}$; according to the assumed static scheme, they depend on the inclination $\theta_{p}$ as follows:

$$
T_{s}=\frac{1}{3} Q_{p} \sin \theta_{r} \cos \theta_{r} ; \quad W_{s}=Q_{p} \frac{3-\cos ^{2} \theta_{r}}{3}
$$

where $\theta_{r}$ is the inclination angle of the hip rafter, depending on $\theta_{p}$ through the expression:

$$
\theta_{r}=\tan ^{-1} \frac{\tan \theta_{p}}{\sqrt{2}}
$$




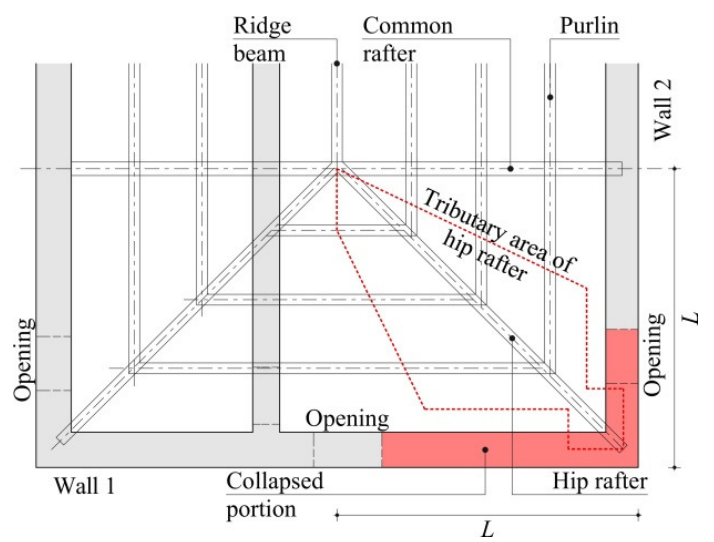

(a)

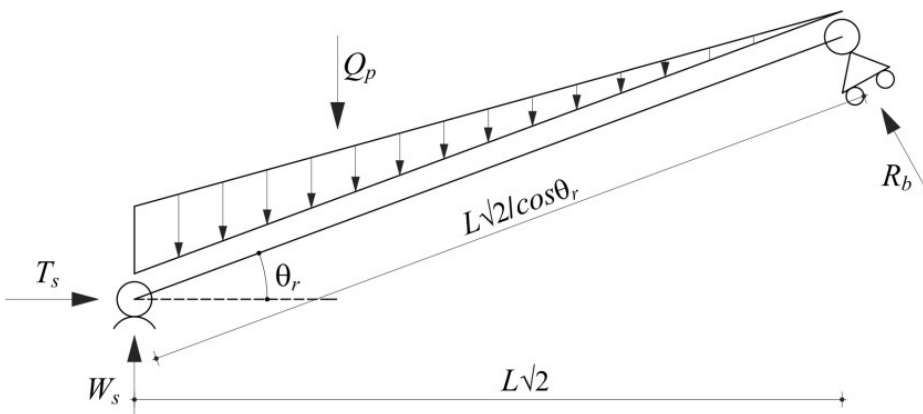

(b)

Figure A.1 Layout of the structure of the wooden roof (a) and static scheme of the hip rafter (b).

APPENDIX B. Calculation of the centre of mass coordinates of the collapsed corner of the case study building

The masses involved in the mechanism of the corner are represented in Figure B.1 by the self-weights of the portions of the walls $\left(W_{0}, W_{1}, W_{2 l}, W_{2 p}, W_{2 u}\right)$, the resultants $\left(W_{s 0}, W_{s 1}, W_{s 2}\right)$ of the uniformly distributed overloads and the vertical action of the hip rafter $\left(W_{s}\right)$. In particular, $W_{s 0}$ is the weight of the concrete curb plus the low wall on the intersection of Walls 1 and 2 , as also reported in Table 1 and Figure 9. The formulations of these forces and the coordinates of their application points are reported in Table B.1. It is worth highlighting that $C_{1}$ and $C_{2}$ are functions of the two variables $\tan \beta_{1}$ and $\tan \beta_{2 u}$, respectively.

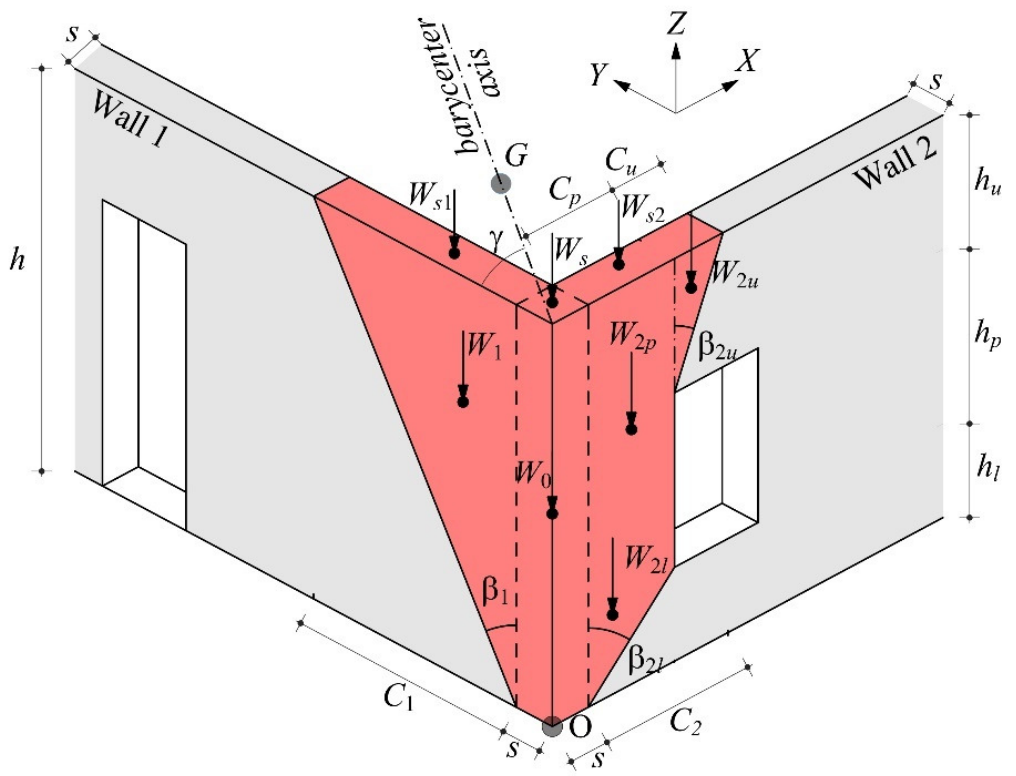

Figure B.1 Axonometric view showing the all the weights involved in the corner mechanism. 


\begin{tabular}{llll}
\hline Involved weights & $x_{j}$ & $y_{j}$ & $z_{j}$ \\
\hline$W_{0}=\gamma s^{2} H$ & $s / 2$ & $s / 2$ & $H / 2$ \\
$W_{s}=Q_{p} \frac{3-\cos ^{2} \theta_{r}}{3}$ & $s / 2$ & $s / 2$ & $H$ \\
$W_{\mathrm{s} 0}=$ overload on intersection of Walls & $s / 2$ & $s / 2$ & $H$ \\
$W_{1}=0.5 \gamma C_{1} H s$ & $s / 2$ & $s+C_{1} / 3$ & $2 H / 3$ \\
$W_{s 1}=q_{1} C_{1}$ & $s / 2$ & $s+C_{1} / 2$ & $H$ \\
$W_{2 l}=0.5 \gamma C_{p} h_{l} s$ & $s+C_{p} / 3$ & $s / 2$ & $2 h_{l} / 3$ \\
$W_{2 p}=\gamma C_{p}\left(h_{p}+h_{u}\right) s$ & $s+C_{p} / 2$ & $s / 2$ & $h_{l}+\left(h_{p}+h_{u}\right) / 2$ \\
$W_{2 u}=0.5 \gamma C_{\mathrm{u}} h_{u} s$ & $s+C_{p}+C_{u} / 3$ & $s / 2$ & $H-h_{u} / 3$ \\
$W_{s 2}=q_{2} C_{2}$ & $s+C_{2} / 2$ & $s / 2$ & $H$
\end{tabular}

The cordinates of the centre of mass $\mathrm{G}$ or $\mathrm{G}_{m}$, depending on the considered phase of motion described in Section 3.2, are:

$$
x_{\mathrm{G}, \mathrm{G}_{m}}=\frac{\sum_{j}\left(W_{j} x_{j}\right)}{\sum_{j} W_{j}} ; \quad y_{\mathrm{G}, \mathrm{G}_{m}}=\frac{\sum_{j}\left(W_{j} y_{j}\right)}{\sum_{j} W_{j}} ; \quad z_{\mathrm{G}, \mathrm{G}_{m}}=\frac{\sum_{j}\left(W_{j} z_{j}\right)}{\sum_{j} W_{j}}
$$

661 For the first phase of motion, the inclination of the vertical plane of rotation with respect to YZ-plane, denoted $\gamma$ in Figure $2 b$ 662 and Figure B.1, is expressed as:

$$
\gamma=\tan ^{-1} \frac{x_{\mathrm{G}}}{y_{\mathrm{G}}}
$$

which still depends on the two variables of the optimization problem.

The solution procedure detailed in Section 4.2 provides the values of $\tan \beta_{1}$ and $\tan \beta_{2 u}$ which minimize the load factor and define the whole geometry of the failing corner. Once defined this geometry, the coordinates of the centre of mass $\mathrm{G}_{m}$ is provided by Eq. (B.1), while the new inclination of the vertical plane of rotation $\gamma_{\mathrm{m}}$ can be found similarly to Eq. (B.2), i.e.:

$$
\gamma_{m}=\tan ^{-1} \frac{x_{\mathrm{G}_{m}}}{y_{\mathrm{G}_{m}}}
$$

\section{REFERENCES}

1. Alecci V, Stipo G, La Brusco A, De Stefano M, Rovero L. Estimating elastic modulus of tuff and brick masonry: A comparison between on-site and laboratory tests. Construction and Building 
Materials 2019; 204: 828-838.

2. Griffith MC, Magenes G, Melis G, Picchi L. Evaluation of out-of-plane stability of unreinforced masonry walls subjected to seismic excitation. Journal of Earthquake Engineering 2003; 7: 141169. DOI: $10.1007 / \mathrm{s} 00264-017-3709-6$.

3. Heyman J. The stone skeleton. International Journal of Solids and Structures 1966; 2(2): 249279. DOI: $10.1016 / 0020-7683(66) 90018-7$.

4. Housner GW. The behavior of inverted pendulum structures during earthquakes. Bulletin of the Seismological Society of America 1963; 53(2): 403-417. DOI: 10.1017/CBO9781107415324.004.

5. Pantò B, Giresini L, Sassu M, Caliò I. Non-linear modeling of masonry churches through a discrete macro-element approach. Earthquake and Structures 2017; 12(2): 223-236.

6. Giresini L, Sassu M, Butenweg C, Alecci V, De Stefano M. Vault macro-element with equivalent trusses in global seismic analyses. Earthquake and Structures 2017; 12(4): 409-423. DOI: 10.12989/eas.2017.12.4.409.

7. Andreini M, De Falco A, Giresini L, Sassu M. Collapse of the historic city walls of Pistoia (Italy): Causes and possible interventions. Applied Mechanics and Materials 2013; 351-352: 1389-1392.

8. Casapulla C, Giresini L, Lourenço PB. Rocking and kinematic approaches for rigid block analysis of masonry walls: State of the art and recent developments. Buildings 2017; 7(3). DOI: 10.3390/buildings 7030069 .

9. Sorrentino L, D'Ayala D, de Felice G, Griffith MCC, Lagomarsino S, Magenes G, et al. Review of out-of-plane seismic assessment techniques applied to existing masonry buildings. International Journal of Architectural Heritage 2016; 11(1): 2-21. DOI: 10.1080/15583058.2016.1237586.

10. Ferreira TM, Costa AA, Costa A. Analysis of the out-of-plane seismic behavior of unreinforced masonry: a literature review. International Journal of Architectural Heritage 2015; 9(8): 949972. DOI: $10.1080 / 15583058.2014 .885996$.

11. Godio M, Beyer K. Evaluation of force-based and displacement-based out-of-plane seismic assessment methods for unreinforced masonry walls through refined model simulations. Earthquake Engineering \& Structural Dynamics 2019; 48(4): 454-475. DOI: https://doi.org/10.1002/eqe.3144.

12. Mistretta F, Stochino F, Sassu M. Structural and thermal retrofitting of masonry walls: An integrated cost-analysis approach for the Italian context. Building and Environment 2019; 155: 127-136.

13. Sassu M, Stochino F, Mistretta F. Assessment method for combine structural and energy retrofitting in masonry buildings. Buildings 2017; 7(71).

14. Giresini L, Fragiacomo M, Sassu M. Rocking analysis of masonry walls interacting with roofs. Engineering Structures 2016; 116: 107-120.

15. Casapulla C, Argiento LU. The comparative role of friction in local out-of-plane mechanisms of masonry buildings. Pushover analysis and experimental investigation. Engineering Structures 2016; 126: 158-173. DOI: 10.1016/j.engstruct.2016.07.036.

16. Walsh K, Dizhur D, Giongo I, Derakhshan H, Ingham J. Predicted versus experimental out-ofplane force-displacement behaviour of unreinforced masonry walls. Structures 2018; 15: 292306.

17. D'Ayala D, Speranza E. Definition of collapse mechanisms and seismic vulnerability of historic masonry buildings. Earthquake Spectra 2003; 19(3): 479-509. DOI: 10.1193/1.1599896.

18. Speranza E. An integrated method for the assessment of the seismic vulnerability of historic buildings. Ph.D. Thesis, University of Bath, UK, 2003.

19. Casapulla C, Maione A, Argiento LU, Speranza E. Corner failure in masonry buildings: An updated macro-modeling approach with frictional resistances. European Journal of Mechanics, 
A/Solids 2018; 70: 213-225. DOI: 10.1016/j.euromechsol.2018.03.003.

20. Giresini L, Solarino F, Paganelli O, Oliveira DV, Froli M. One-sided rocking analysis of corner mechanisms in masonry structures: influence of geometry, energy dissipation, boundary conditions. Soil Dynamics and Earthquake Engineering 2019: in press.

21. Casapulla C, Maione A. Experimental and analytical investigation on the corner failure in masonry buildings: interaction between rocking-sliding and horizontal flexure. International Journal of Architectural Heritage 2018. DOI: 10.1080/15583058.2018.1529206.

22. Lagomarsino S. Seismic assessment of rocking masonry structures. Bulletin of Earthquake Engineering 2015; 13(1): 97-128. DOI: 10.1007/s10518-014-9609-x.

23. Freeman SA. Development and use of capacity spectrum method. Proceedings of the 6th US NCEE Conference on Earthquake Engineering/EERI 1998(Paper 269): 12.

24. Giresini L, Fragiacomo M, Lourenço PB. Comparison between rocking analysis and kinematic analysis for the dynamic out-of-plane behavior of masonry walls. Earthquake Engineering and Structural Dynamics 2015; 44(13): 2359-2376. DOI: 10.1002/eqe.2592.

25. Giresini L. Design strategy for the rocking stability of horizontally restrained masonry walls. In: M. Papadrakakis MF, editor. COMPDYN 2017 6th ECCOMAS Thematic Conference on Computational Methods in Structural Dynamics and Earthquake Engineering, Rhodes Island, Greece: 2017.

26. Giresini L, Sassu M. Horizontally restrained rocking blocks: evaluation of the role of boundary conditions with static and dynamic approaches. Bulletin of Earthquake Engineering 2017; 15(1): 385-410. DOI: 10.1007/s10518-016-9967-7.

27. Lagomarsino S, Cattari S. PERPETUATE guidelines for seismic performance-based assessment of cultural heritage masonry structures. Bulletin of Earthquake Engineering 2015; 13(1): 13-47. DOI: 10.1007/s10518-014-9674-1.

28. Drucker DC. Coulomb friction, plasticity and limit loads. Arm Serv Techn Inf Cent 1953; 2902(85): 1-16.

29. Livesley RK. Limit analysis of structures formed from rigid blocks. International Journal for Numeridal Methods in Engineering 1978; 12(12): 1853-1871.

30. Casapulla C, Maione A. Modelling the dry-contact interface of rigid blocks under torsion and combined loadings: Concavity vs. convexity formulation. International Journal of Non-Linear Mechanics 2018; 99: 86-96. DOI: 10.1016/j.ijnonlinmec.2017.11.002.

31. Casapulla C, Argiento LU. In-plane frictional resistances in dry block masonry walls and rockingsliding failure modes revisited and experimentally validated. Composites Part B: Engineering 2018; 132: 197-213. DOI: 10.1016/j.compositesb.2017.09.013.

32. Lipscombe PR, Pellegrino S. Free rocking of prismatic blocks. Journal of Engineering Mechanics 1993; 119(7): 1387-1410. DOI: 10.1061/(ASCE)0733-9399(1993)119:7(1387).

33. Casapulla C, Giresini L, Argiento LU, Lagomarsino S. Incremental static and dynamic analyses of the out-of-plane response of a masonry church damaged by 2016-2017 Central Italy Earthquakes - Analisi statiche e dinamiche incrementali per la valutazione della risposta fuori piano della facciata di una chiesa. XVII ANIDIS Conference on "L'ingegneria sismica in Italia," 2017.

34. Cattari S, Degli Abbati S, Ottonelli D, Sivori D, Spacone E, Camata G, et al. Task 4.1 Workgroup_Report di sintesi sulle attività svolte sugli edifici in muratura monitorati dall'Osservatorio Sismico delle Strutture, Linea Strutture in Muratura. ReLUIS Report, Rete Dei Laboratori Universitari Di Ingegneria Sismica: 2017.

35. DPC. Osservatorio Sismico delle Strutture OSS Download Service. http://www.mot1.it/ossdownload.

36. Giresini L, Casapulla C, Denysiuk R, Matos J, Sassu M. Fragility curves for free and restrained 
rocking masonry façades in one-sided motion. Engineering Structures 2018; 164: 195-213. DOI: 10.1016/j.engstruct.2018.03.003.

37. Vasconcelos G, Lourenço PB. Experimental characterization of stone masonry in shear and compression. Construction and Building Materials 2009; 23(11): 3337-3345.

38. Lourenço PB, Ramos LF. Characterization of cyclic behavior of dry masonry joints. Journal of Structural Engineering 2004; 130(5): 779-786.

39. Lee HS, Park YJ, Cho TF, You KH. Influence of asperity degradation on the mechanical behavior of rough rock joints under cyclic shear loading. International Journal of Rock Mechanics and Mining Sciences 2001; 38(7): 967-980. DOI: 10.1016/S1365-1609(01)00060-0.

40. Fajfar P. Capacity spectrum method based on inelastic demand spectra. Earthquake Engineering \& Structural Dynamics 1999; 28(9): 979-993. DOI: 10.1002/(SICI)10969845(199909)28:9<979::AID-EQE850>3.0.CO;2-1.

41. EC8-1. Eurocode 8: Design of structures for earthquake resistance-Part 1: General rules, seismic actions and rules for buildings 2004.

42. Ferrero C, Lourenço PB, Calderini C. 2016-2017 Central Italy Earthquake: Seismic Assessment of "Pietro Capuzi" School in Visso (Marche). The 9th International Conference on Computational Methods (ICCM2018), 2018. 